\title{
The metabolic response of $P$. putida KT2442 producing high levels of polyhydroxyalkanoate under single- and multiple-nutrient-limited growth: Highlights from a multi-level omics approach
}

\author{
Ignacio Poblete-Castro ${ }^{1,5^{*}}$, Isabel F Escapa ${ }^{2}$, Christian Jäger ${ }^{3}$, Jacek Puchalka ${ }^{1}$, Carolyn Ming Chi Lam',
} Dietmar Schomburg ${ }^{3}$, María Auxiliadora Prieto ${ }^{2}$ and Vítor AP Martins dos Santos ${ }^{1,4}$

\begin{abstract}
Background: Pseudomonas putida KT2442 is a natural producer of polyhydroxyalkanoates (PHAs), which can substitute petroleum-based non-renewable plastics and form the basis for the production of tailor-made biopolymers. However, despite the substantial body of work on PHA production by P. putida strains, it is not yet clear how the bacterium re-arranges its whole metabolism when it senses the limitation of nitrogen and the excess of fatty acids as carbon source, to result in a large accumulation of PHAs within the cell. In the present study we investigated the metabolic response of KT2442 using a systems biology approach to highlight the differences between single- and multiple-nutrient-limited growth in chemostat cultures.

Results: We found that 26, 62, and 81\% of the cell dry weight consist of PHA under conditions of carbon, dual, and nitrogen limitation, respectively. Under nitrogen limitation a specific PHA production rate of $0.43\left(\mathrm{~g} \cdot(\mathrm{g} \cdot \mathrm{h})^{-1}\right)$ was obtained. The residual biomass was not constant for dual- and strict nitrogen-limiting growth, showing a different feature in comparison to other P. putida strains. Dual limitation resulted in patterns of gene expression, protein level, and metabolite concentrations that substantially differ from those observed under exclusive carbon or nitrogen limitation. The most pronounced differences were found in the energy metabolism, fatty acid metabolism, as well as stress proteins and enzymes belonging to the transport system.

Conclusion: This is the first study where the interrelationship between nutrient limitations and PHA synthesis has been investigated under well-controlled conditions using a system level approach. The knowledge generated will be of great assistance for the development of bioprocesses and further metabolic engineering work in this versatile organism to both enhance and diversify the industrial production of PHAs.
\end{abstract}

Keywords: P. putida KT2442, Nutrient limitation, Systems biology, Polyhydroxyalkanoates

\section{Background}

Microorganisms constantly face fluctuations of nutrient concentrations in their natural environments. One of the common evoked responses by bacteria is the storage of carbon and energy sources, as shown by the

\footnotetext{
* Correspondence: ignacio.pobletecastro@helmholtz-hzi.de 'Systems and Synthetic Biology Group, Helmholtz Centre for Infection Research (HZI), Inhoffenstraße 7, 38124 Braunschweig, Germany Full list of author information is available at the end of the article
}

considerable increase in the accumulation of various compounds, such as glycogen, polyesters, and polyphosphates etc. [1]. The primary feature of these compounds is that they can be readily degraded by the cell to satisfy metabolic demands, thus ensuring its survival during famine. Pseudomonas putida KT2440 is a metabolically versatile bacterium [2] normally found in aerobic and semi-aerobic soil and water habitats [3], which has become an efficient cell factory for the

\section{C) Biomed Central}


biotechnological production of value-added compounds [4]. It synthesizes medium-chain-length polyhydroxyalkanoate (PHA) that exhibit different physical properties than those of the first discovered polyester polyhydroxybutyrate (PHB) [5,6]. PHAs can substitute petroleumbased non-renewable plastics and form the basis for the production of tailor-made biopolymers for medical applications [7], where fermentation strategies [8] and the supplied carbon sources [9] highly influence the final monomer composition of the PHA. However, despite the substantial body of work on PHA production by $P$. putida strains, it is not yet clear how the bacterium re-arranges its whole metabolism when it senses the limitation of an inorganic ( $\mathrm{N}, \mathrm{S}, \mathrm{P}$, or $\mathrm{O})$ nutrient and the excess of fatty acids as carbon source, resulting in a large accumulation of PHAs within the cell. Recently, we demonstrated that this pathway acts as an important energy and carbon buffer under nutrient-limiting conditions that guarantee efficient growth [10]. Inactivation of the pathway for PHA accumulation under low nitrogen growth conditions resulted in oxidation of the excess carbon source, rather than transforming it into biomass or secretable compounds, which could be further reused as carbon or energy sources [11]. Chemostat operation allows the single limitation of carbon or of any desirable nutrient in the culture. It is as well the best alternative to perform controlled and highly reproducible cultivation for studying the phenotype of a given organism [12], especially when applying hightroughput technology to capture the transcriptome, proteome, or metabolome of the cell for a given phenotype. Using continuous cultivation, Egli and Quayle demonstrated that varying the ratio of carbon/nitrogen in the feed medium had a significant influence in the cellular and enzymatic composition on the yeast $H$. polymorpha [13]. In addition, three distinct growth regimes were recognized: namely carbon-, carbon-nitrogen-, and strict nitrogen-limiting growth. By applying those fermentation strategies, P. putida GPo1 (formerly known as $P$. oleovorans) was investigated for its capacity to accumulate PHAs from different carbon sources $[9,14,15]$, proving the high metabolic flexibility of GPo1 which was reflected in part by the broad dual-limiting area between the two single-nutrient limitation (for excellent review, see [16]). One of the most interesting findings is that the dual-nutrient-limiting regime can result in the accumulation of PHA at levels comparable to those under strict nitrogen limitation [17]. As this results in less amounts of carbon used for comparable levels of PHA, this can substantially reduce the production costs.

The release of the $P$. putida KT2440 genome sequence in 2002 [2] has enabled researchers to gain deeper and broader insights into the mechanisms underlying PHA biosynthesis [18-21]. The progress in high-throughput technologies such as transcriptomics, proteomics, and metabolomics has expanded greatly the understanding of the genotype-phenotype relationships in Pseudomonas. As a result, several constrain-based metabolic models of this versatile organism have been developed [22-24]. These models are useful to improve the production of PHAs, especially since the metabolic responses for PHA synthesis, which takes place preferably under the limitation of several nutrients, are complex and so far not well-understood. The work herein described aims to unravel the differences between carbon-, carbon-nitrogen-, and nitrogen-limited cultures, where omic-wide measurements were integrated to interpret the resulting phenotype for each condition in terms of PHA/biomass production in P. putida KT2442. This can contribute to set a basis for further development of new biocatalysts and processes that can contribute to reducing the production cost, which remains the biggest obstacle for the economically viable industrial production of PHAs.

\section{Results and discussion}

\section{Physiological response of Pseudomonas putida under} nutrient-limited conditions

In order to evaluate both the capacity of $P$. putida to produce medium-chain-length polyhydroxyalkanoates (mcl-PHAs) and the global cellular responses at the transcriptome, proteome, and metabolome levels, continuous cultivations were conducted under different nutrient-limited conditions. At least three independent experiments for each nutrient limitation were performed under aerobic chemostat conditions. To achieve metabolic steady-state at a dilution rate $(D)$ of $0.1 \mathrm{~h}^{-1}$, five to eight times the residence volume were necessary to attain constant macroscopic physiological parameters across the time. From continuous and flask-culture cultivations the maximum specific growth rate $\left(\mu_{\max }\right)$ on decanoate was found to be $0.53 \mathrm{~h}^{-1}$ (data not shown). When $D$ approaches $\mu_{\max }$, the amount of PHA decreases within the cell [25]. Therefore, we imposed a low $D\left(0.1 \mathrm{~h}^{-1}\right)$ to obtain as much PHA as possible. Decanoate was employed as the unique carbon and energy source, whereas ammonium $\left[\mathrm{NH}_{4}{ }^{+}\right]$as used as the nitrogen source. We changed the $\left(\mathrm{C}_{0} / \mathrm{N}_{0}\right)$ ratios in the feed medium by keeping the nitrogen concentration invariable and increasing the carbon quantity. We were able to establish three specific environments within the chemostat: carbon- (C), carbon-nitrogen- (dual), and strictly nitrogen- $(\mathrm{N})$ limited cultures, which were confirmed by the analytical measurement of the fermentation broth (Table 1). ${ }^{1} \mathrm{H}$ spectra were recorded from samples taken under all limiting fermentation conditions. In all cases there was no significant accumulation 
Table 1 PHA production and relative monomer composition by P.putida KT2442 in continuous culture at $D=0.1 \mathrm{~h}^{-1}$

\begin{tabular}{|c|c|c|c|c|c|c|c|c|c|c|c|}
\hline \multirow[t]{2}{*}{ Limitation } & $\left(C_{0} / N_{0}\right)^{*}$ & $\mathrm{Y}_{\mathrm{x} / \mathrm{C}}$ & $Y_{X / N}$ & $\left(C_{0} / N_{0}\right)^{b}$ & \multirow{2}{*}{$\begin{array}{l}\text { Residual carbon }^{\text {a }} \\
\text { Borders } \\
\text { (g) }\end{array}$} & \multirow{2}{*}{$\begin{array}{c}\text { Residual nitrogen }{ }^{\mathrm{a}} \\
\text { (g) }\end{array}$} & \multirow{2}{*}{$\begin{array}{l}\mathrm{CDW}^{\mathrm{a}} \\
\left(\mathrm{g}^{-1}\right)\end{array}$} & \multirow{2}{*}{$\begin{array}{c}\text { PHA content }^{\mathrm{a}} \\
\text { (\% CDW) }\end{array}$} & \multicolumn{3}{|c|}{$\begin{array}{l}\text { Monomer } \\
\text { composition } \\
\text { (mol \%) }\end{array}$} \\
\hline & $\left(\mathrm{mol} \mathrm{mol}^{-1}\right)$ & $\left(g^{-1}\right)$ & $\left(\mathrm{g} \mathrm{g}^{-1}\right)$ & $\left(\mathrm{mol} \mathrm{mol}^{-1}\right)$ & & & & & $\mathrm{C} 6$ & $\mathrm{C} 8$ & $\mathrm{C} 10$ \\
\hline Carbon & 5.83 & 1.11 & 9.80 & 10.40 & N.D. & $0.112 \pm 0.01$ & $1.46 \pm 0.04$ & $25.78 \pm 0.97$ & 3.3 & 53.4 & 43.3 \\
\hline Carbon-Nitrogen & 16.56 & 1.16 & 16.67 & & N.D. & N.D. & $4.35 \pm 0.13$ & $61.94 \pm 4.95$ & 4.8 & 42.8 & 52.4 \\
\hline Nitrogen & 26.97 & 1.01 & 17.74 & 20.50 & $1.53 \pm 0.04$ & N.D. & $4.63 \pm 0.14$ & $80.58 \pm 0.24$ & 4.3 & 40.2 & 55.5 \\
\hline
\end{tabular}

a Standard deviation $( \pm$ ) from at least three independent experiments

${ }^{*} \mathrm{C}_{0} / \mathrm{N}_{0}$ : Initial feeding ratio of carbon-nitrogen

N.D., Not detectable

${ }^{\mathrm{b}}$ According to the procedure described by Egly and Quayle (1986)

of acetate or any other soluble small molecular weight metabolite.

To obtain insights into the distribution of the metabolized carbon within the cell, we have performed a carbon mass balance analysis for each condition tested (Figure 1). This was calculated based on number of moles of carbon consumed and generated within the chemostat. The C-mol content in the biomass (PHAfree) was assumed to be constant which corresponds to a molecular weight of $27 \mathrm{~g}(\mathrm{C} \text {-mol biomass })^{-1}$ [26]. The environment which is assigned less $\mathrm{CO}_{2}$ (in terms of percentage) among those tested conditions is the dual limitation. A similar percentage of carbon ended up in PHAs in carbon-nitrogen- and nitrogen-deprived cells. In decanoate and decanoate-ammonium-limited cultures, mass-balances indicated that the entire carbon available in the reaction volume was converted to biomass, $\mathrm{CO}_{2}$, and PHA (Figure 1). As shown in (Figure $2 \mathrm{~A}$ ), the biomass yield on decanoate decreased when the ammonium concentration limited growth, expressing its major effect under strict nitrogen limitation. The physiological response of KT2442 to the nutrient-deprived environments differed in the build-up of biomass for both $\mathrm{C}-\mathrm{N}$ - and $\mathrm{N}$-limited cultures as compared with the $\mathrm{C}$-limited culture. This might be due to the increased pool of metabolites suitable for PHA accumulation in the $\beta$-oxidation pathway, which consequently decreases the buffer of precursor for biomass formation, affecting the energy efficiency not only for strict $\mathrm{N}$-deprived cultures [27], but also for C-N-deprived cells. The PHA yield on decanoate was very similar for both dual and strict nitrogen limitation (Figure 2B). Because of this, the additional carbon source is nearly superfluous, indicating potential for savings on the raw materials. Besides, the imposed carbon/nitrogen ratio to achieve the dual limitation environment (Table 1) was significantly higher than the calculated boundary of this condition, which is known to achieve a higher PHA yield [15]. Remarkably, P. putida KT2442 showed a different behavior compared to $P$. putida GPo1 with regard to

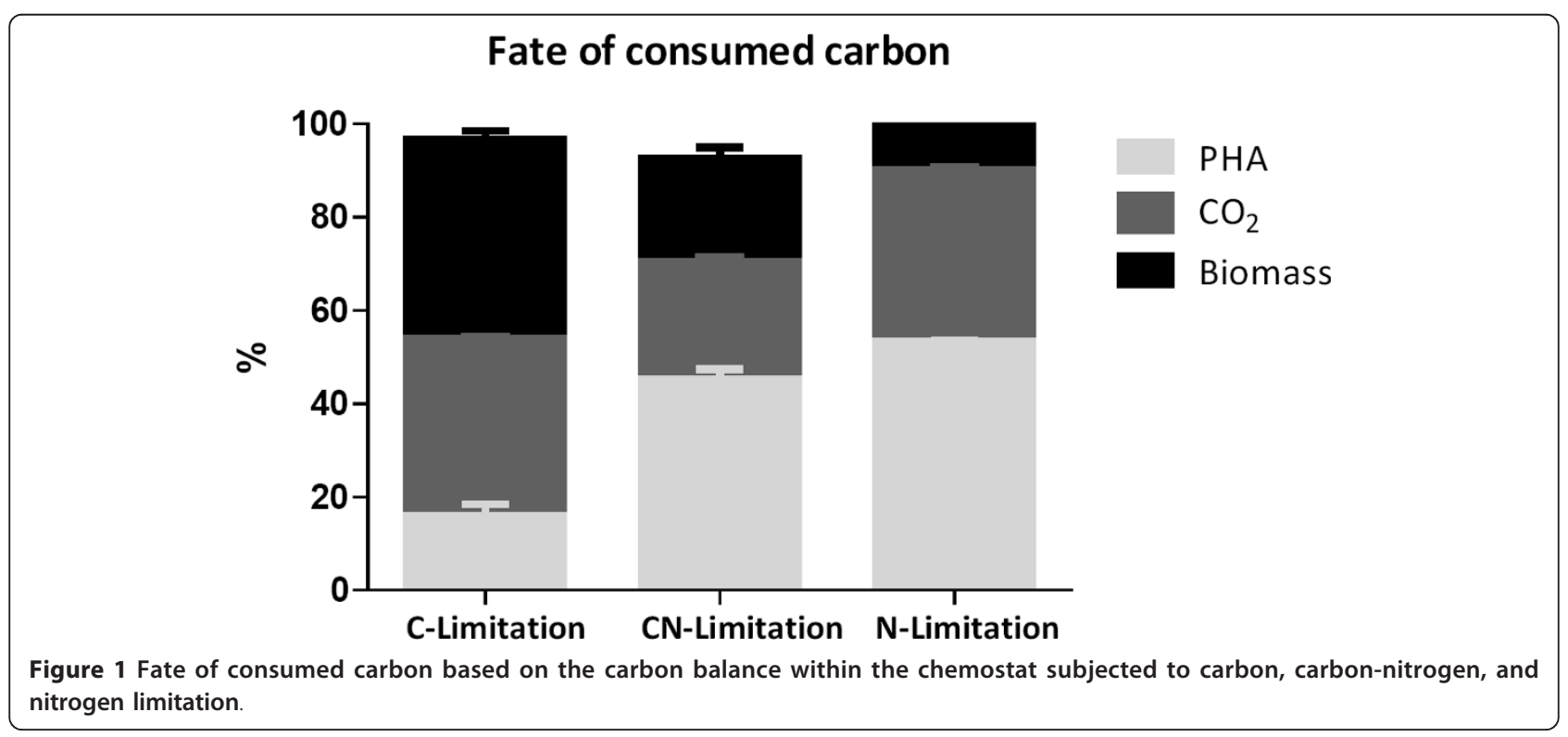




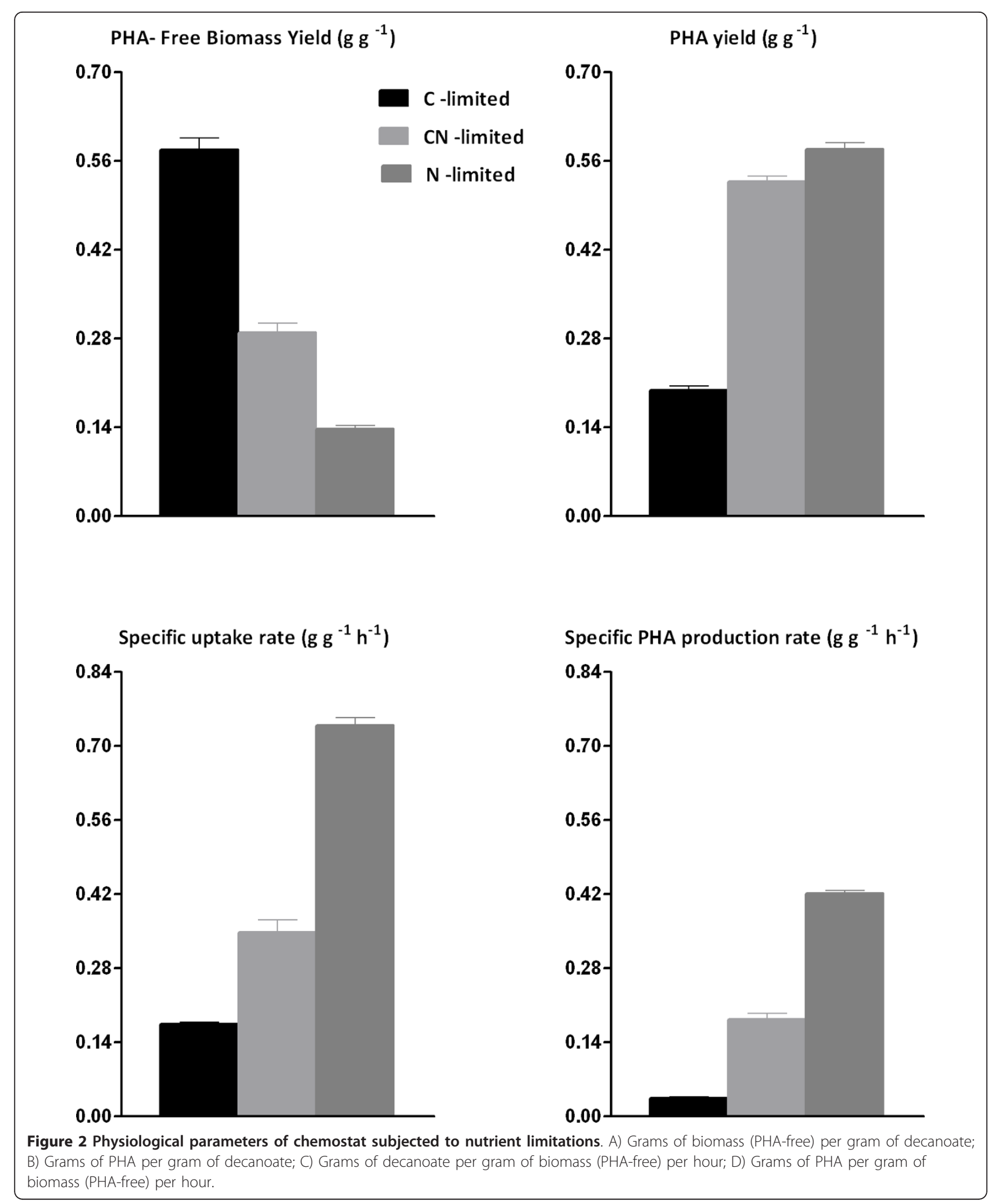


the residual biomass, since for KT2442 this was not constant under $\mathrm{CN}$-and $\mathrm{N}$-limiting growth conditions (Table 1). For GPo1, once the growth condition reached the dual limitation area, the residual biomass remained constant while the PHA content increased proportionally with respect to the $\mathrm{C}_{0} / \mathrm{N}_{0}$ ratio in feed medium [14]. In our study the maximum specific PHA production rate of KT2442 was obtained when the single nitrogen limitation was imposed to the chemostat (Figure $2 \mathrm{D})$, reaching a value of $0.43\left(\mathrm{~g} \cdot(\mathrm{g} \mathrm{h})^{-1}\right)$. This productivity is 3.5-fold higher than the one showed by GPo1 with the same dilution rate while growing on octanoate [14], and 2 -fold higher than the processes using 10-undecenoate as carbon source with also P. putida GPo1 [9].

A) Grams of biomass (PHA-free) per gram of decanoate; B) Grams of PHA per gram of decanoate; C) Grams of decanoate per gram of biomass (PHA-free) per hour; D) Grams of PHA per gram of biomass (PHA-free) per hour

\section{PHA accumulation versus nutrient availability}

To assess the capability of $P$. putida to synthesize mclPHAs, we used gas chromatography to quantify intracellular polyester content and characterize the monomer composition from each individual chemostat culture. The heteropolymer was synthesized under each condition, with the accumulation range of the storage compound in the cell increasing when the $\left(\mathrm{C}_{0} / \mathrm{N}_{0}\right)$ ratio in the feed medium is higher (see Table 1). P. putida KT2442 was capable of synthesizing PHA up to $26 \%$ of its total cell dry weight (CDW) in carbon-limited cultures. A similar PHA concentration (20\% of CDW) was found when KT2442 was grown in oleic acid with a C$\mathrm{mol} / \mathrm{N}-\mathrm{mol}$ ratio of 10 in continuous cultures [25]. Such polymer accumulation is one of the special characteristics shown by $P$. putida strains under carbon-limiting conditions. Nevertheless, not all of them reach high levels of PHA accumulation. In the case of $P$. putida GPo1 the polyester synthesis yielded 2\% of the CDW during carbon-limited growth on heptanoate and octanoate, but with nonanoate PHA accounted for 19 $w \mathrm{t} \%$ of the biomass [15]. Under dual limitation $62 \%$ of the CDW of KT2442 was composed of PHAs, whereas under strict nitrogen-limitation this was $81 \%$.

We were able to identify three saturated monomers in the polyester [21,28] composed of 3.3 mole\% of 3 hydroxyhexanoate (C6), 53.4 mole\% of 3-hydroxyoctanoate (C8), and 43.3 mole\% of 3-hydrodecanoate (C10) when carbon was the limited compound. The monomer composition present in this study is extremely similar when $P$. putida KT2440 was grown in batch cultures supplemented with decanoate [28]. When decanoate is supplied as the only carbon source, the catabolic process occurs through the $\beta$-oxidation pathway. This correlates with the chain length structure detected in the heteropolymer showing C10, C8, and C6 hydroxyl-fatty acids as monomers, as consequence of two carbons loss during each round of the metabolic cycle. Comparing all nutrient-limited regimes, no remarkable difference could be observed in the monomer distribution. However, when ammonia was the limiting inorganic nutrient, a slight increase (of approximately 10\%) in C10 was observed. When both carbon and nitrogen were bellow the detection limit in the chemostat, the monomer composition of the polymer was almost the same as the one observed in nitrogen deprived cultures (Table 1). Further discussion is made below (see fatty acid and PHA metabolism).

\section{Global multi-omics analysis of $P$. putida response under various nutrient limitations \\ Transcriptomics}

Employing genome-wide microarray technology, we quantified the variation in gene expression levels of all three limiting conditions. As we set up our experiments under steady-state, the measurements reflected a snapshot of the metabolic state under the desirable growth limitation by nitrogen or carbon-nitrogen. Three independent biological replicates were analyzed statistically after hybridization. The conditions of strict nitrogen limitation and carbon-nitrogen limitation were compared independently to carbon limitation, i.e. $\mathrm{N}$ vs. C and $\mathrm{CN}$ vs. $\mathrm{C}$, respectively. The resulting intensities were treated using a different package from the Bioconductor suite (see material and methods). The classification of the resulting variations in gene expression were based on Cluster of Orthologous Groups (COG) (http:// www.ncbi.nlm.nih.gov/COG/grace/cogenome.cgi?g=287) and illustrated in Additional file 1: Figure S1. In total, 215 genes were differentially expressed $(P<0.05)$, from which $36 \%$ of their gene products were assigned as having unknown function (Addtional file 2: Table S1). The analysis of $\mathrm{N}$ vs. $\mathrm{C}$ and $\mathrm{CN}$ vs. $\mathrm{C}$ revealed 42 and 31 upregulated genes, while those that had a fold change less than 0.5 -fold were 17 and 125, respectively (Additional file 2: Table S1). As such, the $\mathrm{N}$ vs. $\mathrm{C}$ and $\mathrm{CN}$ vs. $\mathrm{C}$ comparisons shared 20 Open Reading Frames (in grey background Table 2), with 11 showing more than 2 -fold differential expression (Table 2).

\section{Proteomics}

Proteome profiling of Pseudomonas putida was performed using two-dimensional electrophoresis gels for each limiting condition to gain insight into the PHA accumulation machinery. As performed in the transcriptome analysis the gels from $\mathrm{N}$ - and $\mathrm{CN}$-limited conditions were overlapped against the gel of C-limitation (master gel). The proteomic profile for the CN vs. C exhibited only 17 spots with differential expression (DE). 
Table 2 Selected genes differentially expressed within nitrogen ( $\mathrm{N}$ ) or carbon-nitrogen (C-N) limited cultures relative to carbon limited chemostat cultures

\begin{tabular}{|c|c|c|c|c|}
\hline \multirow[t]{2}{*}{ Cellular role category } & \multirow[t]{2}{*}{ Locus tag } & \multirow[t]{2}{*}{ Description } & \multicolumn{2}{|c|}{ Fold change } \\
\hline & & & $\underline{N}$ & $\mathrm{C}-\mathrm{N}$ \\
\hline \multicolumn{5}{|l|}{ Energy metabolism } \\
\hline & PP2638 & Cellulose synthase operon $C$ putative & 3.9 & 4.3 \\
\hline & PP0813 & Cytochrome $o$ ubiquinol oxidase subunit I & 5.0 & 1.2 \\
\hline & PP0814 & Cytochrome o ubiquinol oxidase subunit III & 4.4 & -1.1 \\
\hline & PP4050 & Glycogen synthase & 3.1 & 1.3 \\
\hline & PP0555 & Acetoin dehydrogenase alpha subunit & -6.7 & -8.3 \\
\hline & PP0556 & Acetoin catabolism protein & -3.7 & -4.6 \\
\hline & PP0554 & Acetoin dehydrogenase beta subunit & -4.6 & -4.2 \\
\hline & PP0553 & Acetoin dehydrogenase dihydrolipoamide & -5.3 & -4.0 \\
\hline & PP0557 & Acetoin catabolism regulatory protein & -3.4 & -3.6 \\
\hline & PP2149 & Glyceraldehyde 3-phospate dehydrogenase & 1.5 & -3.7 \\
\hline & PP4715 & Triosephosphate isomerase & 1.9 & -3.3 \\
\hline & PP4737 & D-lactate dehydrogenase putative & $-2.6^{*}$ & -3.1 \\
\hline & PP0545 & Aldehyde dehydrogenase family protein & -1.9 & -3.1 \\
\hline & PP1083 & Bacterioferritin-associated ferredoxin putative & 1.4 & 2.9 \\
\hline & PP3071 & Acetoacetyl-CoA synthetase putative & 1.1 & -2.6 \\
\hline & PP4736 & L- lactate dehydrogenase & -1.1 & -2.5 \\
\hline & PP4192 & Succinate dehydrogenase hydrophobic & $3.9^{*}$ & -2.4 \\
\hline & PP4193 & Succinate dehydrogenase cytochrome & $2.7^{*}$ & -2.2 \\
\hline \multicolumn{5}{|c|}{ Amino acid transport and biosynthesis } \\
\hline & PP4842 & Branched-chain amino acid $A B C$ transport & 15.9 & 5.8 \\
\hline & PP4841 & Branched-chain amino acid $A B C$ transport & 7.3 & 4.5 \\
\hline & PP5075 & Glutamate synthase small subunit & 3.4 & 1.2 \\
\hline & PP3021 & Transporter LysE family & -1.4 & 2.2 \\
\hline \multicolumn{5}{|c|}{ Transport and binding proteins } \\
\hline & PP4147 & Peptide $A B C$ transporter & -1.1 & -2.7 \\
\hline & PP1076 & Glycerol uptake facilitator protein & 1.4 & -2.9 \\
\hline & PP3954 & Periplasmic binding protein putative & -1.9 & -3.2 \\
\hline \multicolumn{5}{|l|}{ Nitrogen metabolism } \\
\hline & PP5234 & Nitrogen regulatory protein P-II & 25.1 & 12.2 \\
\hline & PP5233 & Ammonium transporter & 13.7 & 2.6 \\
\hline & PP1705 & Nitrate reductase & $4.1^{*}$ & 5.2 \\
\hline & PP1703 & Assimilatory nitrate reductase putative & $2.3^{*}$ & 3.6 \\
\hline & PP2094 & Nitrate-binding protein & $4.5^{*}$ & 2.6 \\
\hline & PP2092 & Nitrate transporter & $2.3^{*}$ & 3.7 \\
\hline & PP2846 & Urease accessory protein UreE & $3.1^{*}$ & 2.8 \\
\hline & PP2847 & Urease accessory protein UreJ & $2.6^{*}$ & 2.5 \\
\hline & PP2843 & Urease gamma subunit UreA & 2.3 & 2.2 \\
\hline \multicolumn{5}{|c|}{ Fatty acid and phospholipid metabolism } \\
\hline & PP2050 & Conserved hypothetical protein & 28.4 & 1.2 \\
\hline & PP2051 & Acetyl-CoA acetyltransferase & 27.9 & -1.1 \\
\hline & PP2049 & Alcohol dehydrogenase iron-containing & 28.3 & 1.1 \\
\hline & PP2047 & 3-hydroxyacyl-CoA dehydrogenase family & 20.9 & 1.1 \\
\hline & PP2048 & Acyl-CoA dehydrogenase putative & 19.8 & 1.5 \\
\hline & PP4550 & Long-chain-fatty-acid-CoA ligase & 4.2 & 1.5 \\
\hline \multicolumn{5}{|l|}{ Stress response } \\
\hline & PP2437 & Acyl-CoA dehydrogenase putative & -1.4 & -3.2 \\
\hline & PP3781 & Oxygen-independent Coproporphyrinogen III & 7.5 & -1.1 \\
\hline & PP1185 & Outer membrane protein $\mathrm{H} 1$ & 6.6 & $2.0^{*}$ \\
\hline
\end{tabular}


Table 2 Selected genes differentially expressed within nitrogen ( $\mathrm{N}$ ) or carbon-nitrogen (C-N) limited cultures relative to carbon limited chemostat cultures (Continued)

\begin{tabular}{|c|c|c|c|c|}
\hline & PP1360 & Chaperonin, 10 kDa & 3.4 & -1.1 \\
\hline \multicolumn{5}{|l|}{ Other functions } \\
\hline & PP2141 & Hypothetical protein & -4.0 & -3.1 \\
\hline & PP1659 & Hypothetical protein & -4.8 & -2.4 \\
\hline & PP0765 & Hypothetical protein & -7.1 & -2.8 \\
\hline & PP2685 & Hypothetical protein & 11.1 & 4.0 \\
\hline & PP2686 & Transglutaminase-like superfamily & 6.6 & 4.6 \\
\hline & PP2687 & Conserved hypothetical protein & 7.1 & 2.6 \\
\hline & PP2689 & Endoribonuclease putative & 1.7 & 2.5 \\
\hline
\end{tabular}

* $0.1>P$-value $>0.05$

* Bold font indicates matching gene expression of $\mathrm{N}$ vs. $\mathrm{C}$ and $\mathrm{CN}$ vs. $\mathrm{C}$

A completely different scenario was detected by overlapping the nitrogen limiting growth gel with the master gel, giving 74 spots with differential expression. After searching the sequence similarity for protein identification (see materials and methods), out of these 74 spots, 45 met the requirements for protein identification. The proteins were classified using COGs and JCVI-CMR (http://cmr.jcvi.org/cgi-bin/CMR/CmrHomePage.cgi) and presented in Table 3 . The transcriptome response based on DNA microarray was compared to the proteome data. For $\mathrm{C} / \mathrm{N}$ vs. $\mathrm{C}$ limitation only 5 proteins matched with their corresponding gene expression, and for $\mathrm{N}$ vs. C limitation 6 fell into this category (Table 3, in grey background). Although, 2-D PAGE proteome analysis is one of the most employed techniques in the field, it did not capture the entire proteome of the tested conditions (no identification of $\mathrm{PhaC}$ or PhaF), thus having a significant impact on the comparison.

Table 3 Genes differentially expressed of the PHA metabolic pathway within nitrogen $(\mathrm{N})$ or carbonnitrogen (C-N) limited cultures relative to carbon limited chemostat cultures

\begin{tabular}{lcccr}
\hline Gene name & Locus tag & Description & \multicolumn{2}{c}{ Fold change } \\
& & & $\mathrm{N}$ & C-N \\
\cline { 4 - 5 } phal $^{*}$ & PP5008 & PHA granule-associated & 6.1 & 2.5 \\
phaF & PP5007 & PHA granule-associated & $3.1^{*}$ & 2.3 \\
phaC1 & PP5003 & PHA polymerase & $3.4^{*}$ & 1.0 \\
phaC2 & PP5005 & PHA polymerase & 1.2 & 1.1 \\
phaZ & PP5004 & PHA depolymerase & $2.1^{*}$ & 1.3 \\
phaD & PP5006 & Transcriptional regulator & 1.2 & 1.3 \\
phaJ & PP4552 & Enoyl-CoA hydratase & 1.5 & 1.6 \\
phaG & PP1408 & Acyl-transferase & $3.3^{*}$ & 2.2 \\
\hline * 0.1 $>$ P-value $>$ 0.05 & & & \\
$*$ Bold font indicates matching gene expression of N vs. C and CN vs. C
\end{tabular}

Relationships and discrepancies between transcripts and proteins

The correlation between increased transcripts and their corresponding protein abundance is very poor as shown in Table 3 for $\mathrm{CN}$ vs. $\mathrm{C}$ and $\mathrm{N}$ vs. $\mathrm{C}$ comparisons. Earlier studies have previously shown this trend between mRNA and protein levels [29-31]. It has mainly been attributed to post-transcriptional events [29] e.g. translation efficiency or protein degradation, and/or false-positive results either on the mRNA or protein levels [32]. The generated gels from the proteome analysis in this study were made in triplicate for each tested condition, giving a confident proteome profile. Therefore, the high discrepancy between the transcript and protein expression levels, for both comparisons, might be evoked by a post-transcriptional regulation. This is supported by the number of differentially expressed genes - especially while comparing $\mathrm{CN}$ vs. $\mathrm{C}$ limitation - and the matched protein/mRNA abundance. Nevertheless, to fully confirm this hypothesis further studies should be addressed with more accurate techniques by which thousands of proteins can be quantified and compared [33]. In this study, a surprisingly high number of downregulated genes in $\mathrm{CN}$-limitation relative to $\mathrm{C}$-limitation was found (Additional file 1: Figure S1). This highly differs from the proteome profile (Table 3 ). In addition, it is interesting to see how $P$. putida KT2442 displays many changes at the transcription level, but at the translation level the final response is quite conservative upon $\mathrm{CN}$ limitation. One could propose that under $\mathrm{CN}$-limitation the coupling between anabolism and catabolism is tighter than N-limitation, as it can be seen by the residual biomass formation under the mentioned conditions (Figure 2). Therefore, it seems that dual limitation is more similar to C-limiting than $\mathrm{N}$-limiting cultures, since the proteome profile - which is a closer link than transcriptome to the final phenotype of the cell - did not have a significant change for the dual limitation relative to strict carbon limitation (Table 3). 


\section{Metabolomics}

Applying metabolome analysis, the peak areas of the Entner-Doudoroff-pathway and TCA cycle intermediates, and amino acids were determined and the mass corresponding masses quantified as described in Materials and Methods. The reproducibility of the analytical protocols (technical reproducibility) was determined for every sample set by establishing the relative standard deviation (RSD) among three samples harvested from the same fermentor. An average RSD of $22 \%$ was obtained for the technical reproducibility analyzed by GC-MS. In addition, an average RSD was calculated for specific metabolites in cells grown under the same condition in two independent cultivations $\left(\mathrm{RSD}_{\mathrm{C} \text {-limitation }}\right.$ $\left.32 \%, \mathrm{RSD}_{\mathrm{CN} \text {-limitation }} 28 \%, \mathrm{RSD}_{\mathrm{N} \text {-limitation }} 49 \%\right)$. A Pearson correlation factor of 0.97 between measured metabolites in $\mathrm{C}$ - and $\mathrm{CN}$-limitation was determined, which indicates slight differences in metabolite levels in the central carbon metabolism. Between $\mathrm{C}$ - and N-limitation, a Pearson correlation factor of 0.84 was obtained, but the biological variances were clearly higher in $\mathrm{N}$ limitation within independent cultivations. Because of the high variability of specific metabolites among biological replicates, most probably due to the sampling procedure since we did not have a fast sampling device for quenching samples, their concentration levels could not be determined. Therefore, these metabolites were excluded from the discussion. Globally, 233 intracellular compounds were found in the chromatogram (containing systemic peaks derivates). According to their retention times and mass spectra, 80 metabolites could be identified by comparison to our in-house libraries.

\section{Integrated analysis of the various "omics" results under different nutrient limitations}

The profile of metabolites in a cell at any given moment is closely related to the perturbation of gene expression and the modulation of protein function [34]. All together, the data from these three levels of cellular response offer a more comprehensive global view of the changes taking place under limitation of carbon and/or nitrogen sources.

\section{(i) Nutrient limitation leads to modulation of several transport systems}

Pseudomonas putida KT2440 possesses approximately 370 cytoplasmic membrane transport systems, a feature that confers a greater transport capability to this versatile bacterium [35]. When comparing $\mathrm{N}$ - versus C-limitation, both the $\mathrm{ABC}$ transporter that belongs to the ATP-binding cassette superfamily (encoded by PP_4864) and the general amino acid system AapP (encoded by PP_1300) were found, by proteomics, to have increased enzyme levels. In contrast, the genes encoding for proteins responsible for importing specific amino acids, e.g. glutamate, aspartate, and other compounds across the membrane, as well as periplasmic $\mathrm{ABC}$ transporters (encoded by PP_1071, PP_0282, PP_0112, PP_0885) (Table 3) were clearly downregulated. The dual limitation triggered high induction of only one $\mathrm{ABC}$ transporter, LivK (26.4-fold), which is one of the five proteins that form the branched-chain amino acid ABC transporter system and whose transcript level was found also to be induced (Table 2). Another amino acid transporter differentially expressed was LysE (encoded by PP_3021), as well as the urea assimilation system (UreE, UreJ, and UreA). The activation of urease may increase competitive fitness of bacteria under nitrogen-limiting conditions, since urease catalyzes the hydrolysis of urea to yield ammonia and carbamate [36]. For instance, many pathogens are able to colonize several niches in the human body due to the capacity of synthesizing nitrogen from urea, which helps them to overcome nitrogen limitation and thereby increase their potential to thrive in the host [37].

The activation of the major porin protein OprF (encoded by PP_2089) in Pseudomonas, was indicated by the variation of the protein production by 2.6 -fold and 5.4-fold in $\mathrm{CN}$ vs. $\mathrm{C}$ and $\mathrm{N}$ vs. $\mathrm{C}$, respectively. OprF is involved in conferring several degrees of permeability to the cell [38] and has been described as one the intrinsic factors in $P$. aeruginosa that strongly increases its resistance to antibiotics $[39,40]$. Another member of the porin family OprD (encoded by PP_1206) was exclusively induced by the dual limitation. The specific porin OprD has been shown to be implicated in the uptake of basic amino acids $[41,42]$, facilitating their diffusion across the membrane. Such behavior indicates that the outer membrane composition follows a sensitive response to different signals, e.g. nutrient and/or metabolite concentrations, which is reflected in the modulation of specific transporters as needed. Furthermore, based on the high incorporation level of OprH exclusively under $\mathrm{N}$ vs. $\mathrm{C}$ limitation, it seems that $\mathrm{OprH}$, an outer membrane protein mainly responsible for membrane stabilization $[43,44]$, has an important role in KT2442 to cope with such elevated concentrations of decanoate used to reach the strict nitrogen limitation.

\section{(ii) Fatty acid metabolism and PHA synthesis}

Fluorescent pseudomonads are able to metabolize a broad range of fatty acids. The cells first convert the fatty acid to the corresponding acyl-CoA thioester, which is further oxidized by the $\beta$-oxidation cycle [45]. In this regard, three sets of FadAB genes have been described in KT2440 [46]: FadB and FadA (PP_2136 and PP_2137), FadBx and FadAx (PP_2214 and PP_2215), and PP_2047 and PP_2048, which encode 3-hydroxyacyl-CoA dehydrogenase (FadB-like) and acyl-CoA dehydrogenase (FadE-like), respectively $[18,19]$. Mutations of 
those genes showed that FadB and FadA played important roles in fatty acid degradation. However, the deletion of these genes could not completely block the $\beta$ oxidation pathway and mutant strains produced PHA with longer chain monomers, likely due to a slower or defective $\beta$-oxidation pathway $[18,19,47]$. Several intermediates from the cycle, such as 2-trans-enoyl CoA, $(S)$ 3-hydroxyacyl-CoA, and 3-ketoacyl-CoA, may serve as precursors for PHA synthesis. The latter intermediate is also cleaved by a $\beta$-ketothiolase to yield acetyl-CoA and acyl-CoA, which have two less carbons compared with the one that initially entered the cycle. It is still unclear which intermediate contributes the most to produce the PHA polymerase substrate $(R)-3-\mathrm{OH}$-acyl-CoA.

Relative to carbon limitation, dual limitation showed no upregulation of enzymes or genes belonging to the $\beta$-oxidation pathway (Figure 3). It was not the case for the PHA gene cluster, where the phasins PhaI and PhaF were found upregulated (Table 4). The application of non-standard accumulating conditions e.g. all nutrients in excess or carbon limitation, has been reported to lead to the biosynthesis of polyesters [48,49]. Nevertheless, a clear explanation of this phenomenon remains unknown. Based on our findings, we argue that $P$. putida KT2442 has a metabolic system in which the constant channeling of precursors for PHA accumulation occurs even under carbon limitation since the activity of the $\beta$-oxidation pathway (fatty acid metabolism) and the PHA synthases (PhaC) did not change significantly between dual vs. carbon limitation (Table 2, 4, and 3). Dual limitation resulted in $60 \%$ of the CDW as PHA. In this case the phasins may segregate and distribute more PHA [50] than under carbon limitation, thus explaining their induction. In contrast, one set of proteins that showed a high expression level under $\mathrm{N}$ vs. $\mathrm{C}$ were related to the $\beta$-oxidation cycle (Table 3 ). Indeed, this is the main route to metabolize aliphatic fatty acids, where the synthesis of two key metabolites, $(S)$-3hydroxy-acyl-CoA and acetyl-CoA, occurs simultaneously [45]. The most over-expressed proteins in the fatty acid group, 3-hydroxyacyl-CoA dehydrogenase (encoded by PP_2047) and acetoacetyl-CoA thiolase (encoded by PP_2051), matched the remarkable induction of the gene cluster (PP_2047-PP_2051) at the mRNA level (Table 3). Recent evidence indicates that the protein product of the PP_2047 and PP_2048 open reading frames play very important roles in defining the PHA composition when fatty acids are the carbon source (Liu et al., 2011). In this respect, the observed enrichment in $\mathrm{C} 10$ found in the chemostat subjected to strict nitrogen limitation could be assigned to this dehydrogenase (PP_2047), since a dramatic shift was obtained in the monomer composition when the gene encoding this enzyme was knocked-out in KT2442 (Liu

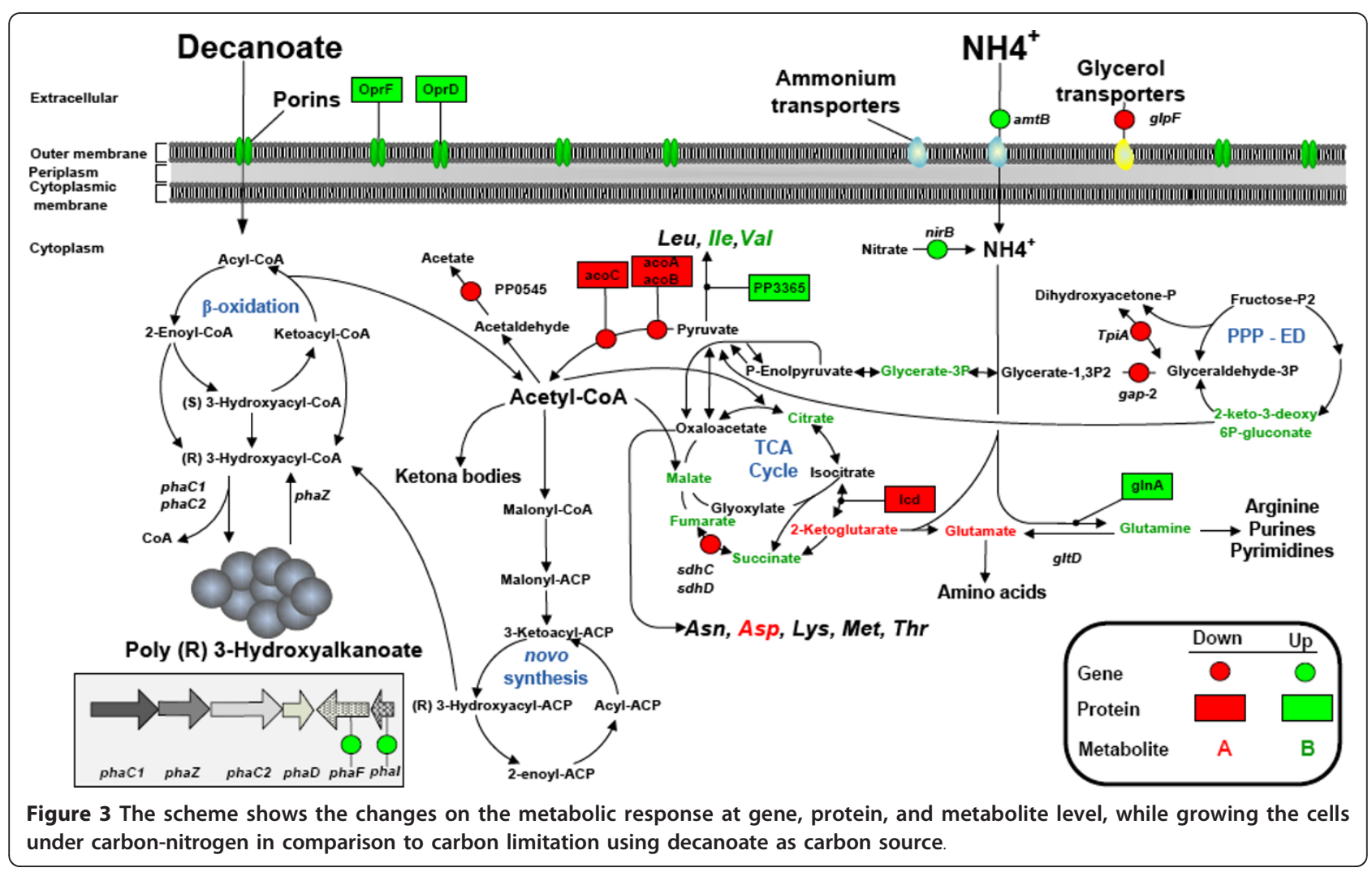


et al., 2011). Nevertheless, under dual limitation a similar monomer composition was found where no overexpression of PP_2047 could be observed at the proteome level. Based on these results, the defined monomer composition is a much more complex mechanism, where nutrients availability seems to be another important factor in controlling the fate of carbon in PHA synthesis. The protein FadA, which is the product of gene PP_2137 (Table 3) that belongs to the first set of genes coding for the $\beta$-oxidation pathway in P. putida converting 3-ketoacyl-CoA into acetyl-CoA and acyl-CoA, is responsible for the last step in the $\beta$-oxidation pathway and its expression showed a 3.0-fold increase. Furthermore, FadB was identified in two different spots where the average of its protein abundance was about 3-fold. AccC-1 (encoded by PP_0558), an important protein involved in PHA synthesis (Huijberts et al., 1992), presented an 8.3-fold induction at $\mathrm{N}$ vs. C. It is noteworthy that this enzyme leads the initial step from acetyl-CoA to fatty acid de novo synthesis via malonylCoA and it is normally activated while growing on nonPHA-related substrates such as sugar and gluconate [51]. Taking all together, we could capture the difference at single molecular levels within the $\beta$-oxidation pathway which is known to generate intermediates for both biomass and PHA synthesis while fatty acids are supplied as carbon sources [25]. Huijbert and co-workers hypothesized that, at certain level of $\mathrm{C} / \mathrm{N}$ ratio, the catabolic cycle for fatty acids switches its precursor preference, where instead of replenishing its intermediates for further oxidation, they are converted to PHA monomers. The finding in this study, where the residual biomass is not constant for $\mathrm{C} / \mathrm{N}$ - and $\mathrm{N}$-limited cultures which was not observed in previous reports using $P$. putida GPo1 - can be explain by the fact that several enzymes (FadB, FadA) and the gene cluster PP_2047PP_2051 were differentially expressed when comparing $\mathrm{N}$ - vs. C-limiting growth. To further investigate which genes contributed most to this difference, we performed a transcriptome analysis comparing $\mathrm{N}$ vs. $\mathrm{CN}$ limitation using a very strict cut-off (Fold change $>3.5$ and a $P$ value $<0.03$ ). Only 9 genes fell into this group (Additonal file 3: Table S2). The gene cluster PP_2047-PP_2051 exhibits more than 10-fold change in expression, and especially 3-hydroxyacyl-CoA dehydrogenase (encoded by PP_2047) was induced by 25 -folds (Additonal file 3: Table S2). Based on this result, we can postulate that these ORFs are responsible for the diminishing on biomass formation, where the generated precursors within the oxidation cycle are redirected to PHA synthesis. On top of this, AtoB (encoded by PP_2051) is an enzyme that converts acetyl-CoA into acetoacetyl-CoA, a competing pathway for the TCA cycle. By a chain elongation process the acetyl-CoA is further condensed to 3-
hydroxyacyl-CoA which is finally involved in PHA synthesis [52], thus explaining the variation on biomass formation while comparing $\mathrm{N}$ vs. $\mathrm{CN}$-limited growth in P. putida KT2442. With regard to the degradation system of the PHA granule in P. putida strains, recent studies have elucidated its influence on the metabolic balance of the cell. A negative PhaZ mutant strain from P. putida KT2442 had shown no increase in PHA yield but a reduction in the biomass concentration relative to the wild-type in batch cultures [10]. In the same study, it was demonstrated that PHA metabolism is an ongoing cycle where synthesis and degradation of the polyester is a simultaneous process. The same result was found using $P$. putida $\mathrm{U}$, where the activities of $\mathrm{PhaC}$ and PhaZ are concomitantly active [53]. It is worth to mention that in batch processes the kinetic limitation of a single nutrient takes place. As the present study was performed using chemostat cultures, the cells are always exponentially growing, and therefore the physiological state of the cells differs from that shown in batch culture. The expression level of the phaZ depolymerase gene was not affected by the dual limitation in comparison to carbon limitation (Table 4). This was not the case when nitrogen was the single limiting nutrient, showing a increase in phaZ expression (Table 4). In agreement with one of our previous reports, the transcription levels of phaC and phaZ are highly correlated [20], thus indicating that such regulatory system is independent of the cultivation mode. This result supports the postulate that at high production rate of PHAs, the expression of the PhaZ is needed for the efficient production of the polyester [54,55].

\section{(iii) Energy metabolism}

TCA Cycle Once the fatty acid is oxidized in subsequent steps within the $\beta$-oxidization cycle, acetyl-CoA is produced in the TCA cycle for energy generation and to sustain biomass and maintenance of the cell. Little is known about the regulation of this pathway when fatty acids are used as a carbon source and several nutrient limitations are imposed on the system. This is even more complex since intermediates and co-factors of the Krebs cycle inhibit various enzymatic reactions within the cycle itself. For instance, NADH inhibits the isocitrate dehydrogenase, 2-ketoglutarate dehydrogenase, and isocitrate synthase. A crucial question is how the cells orchestres its metabolism to generate the energy for sustaining growth while simultaneously large quantities of PHA is being synthesized. The F0F1 synthase subunit alpha AtpA (encoded by PP_5415) (oxidative phosphorylation) was overproduced in dual and strict nitrogen limitation as compared to the carbon limitation. According to this finding, oxygen may also have an effect on the PHA production capacity in $P$. putida KT2442, but this statement still needs to be tested. The increased 
Table 4 Change in protein expression in response to nitrogen and carbon-nitrogen limitation in comparison with carbon-limitation

\begin{tabular}{|c|c|c|c|c|c|c|}
\hline & \multirow[t]{2}{*}{ Locus tag } & \multirow[t]{2}{*}{ Gene symbol } & \multicolumn{2}{|c|}{ Protein } & \multicolumn{2}{|c|}{ Transcript } \\
\hline & & & D.E & Peptides No. ${ }^{a}$ & Fold change & $P$-value \\
\hline \multicolumn{7}{|l|}{ Differential protein expression of $C N$ vs. $C$} \\
\hline \multicolumn{7}{|l|}{ Energy metabolism } \\
\hline ATP synthase $F 1, \alpha$-sub & PP5415 & AtpA & only in $C N$ & 12 & ND & ND \\
\hline Glycogen debranching & PP4055 & $G \lg X$ & 4.5 & 20 & 1.9 & 0.05 \\
\hline Acetolactate synthase & PP3365 & & 3.5 & 15 & -1.0 & n.s. \\
\hline Isocitrate dehydrogenase & PP4011 & $I C D$ & -5.0 & 28 & -1.4 & n.s. \\
\hline Acetoin dehydrogenase $^{*} \alpha$-sub & PP0555 & AcoA & & 7 & -8.3 & 0 \\
\hline Acetoin dehydrogenase $\beta$-sub & PP0554 & AcoB & -5.6 & 23 & -4.2 & 0 \\
\hline Acetoin dehydrogenase & PP0553 & AcoC & -3.7 & 10 & -4.0 & 0 \\
\hline \multicolumn{7}{|l|}{ Nitrogen metabolism } \\
\hline Nitrogen regulatory protein P-II & PP5234 & GlnK & only in $C N$ & 6 & 10.4 & 0 \\
\hline \multicolumn{7}{|l|}{ Protein synthesis } \\
\hline Elongation factor Tu & PP0452 & TUF-2 & only in $C N$ & 16 & -1.6 & n.s. \\
\hline \multicolumn{7}{|l|}{$\underline{\text { Amino acid transport and biosynthesis }}$} \\
\hline Branched-chain amino acid $A B C$ trans & PP4841 & LivK & 26.4 & 22 & 4.5 & 0 \\
\hline Glutamine synthetase & PP5046 & $G \ln A$ & 2.2 & 28 & 1.0 & n.s. \\
\hline \multicolumn{7}{|l|}{$\underline{\text { Signal transduction }}$} \\
\hline$\overline{\text { Response regulator }}$ & PP5048 & NtrC & 6.7 & 43 & 1.7 & n.s. \\
\hline \multicolumn{7}{|l|}{ Transport and binding protein } \\
\hline Outer membrane porin & PP1206 & OprD & 2.7 & 11 & -1.1 & n.s. \\
\hline Outer membrane porin & PP2089 & OprF & 2.6 & 21 & 1.2 & n.s. \\
\hline \multicolumn{7}{|l|}{ Purine ribonucleotide biosynthesis } \\
\hline adenylosuccinate synthetase & PP4889 & PurA & -4.4 & 16 & -1.1 & n.s. \\
\hline Hypothetical protein & PP2384 & & -2.8 & 6 & 1.5 & n.s. \\
\hline Protein fate & PP0980 & PepA & -2.3 & 30 & 1.0 & n.s. \\
\hline \multicolumn{7}{|l|}{ Differential protein expression of $\mathrm{N}$ vs. C } \\
\hline \multicolumn{7}{|l|}{ Energy metabolism } \\
\hline Succinyl-CoA synthetase & PP4185 & SucD & only in N & 8 & 1.2 & n.s. \\
\hline ATP synthase F1, alpha sub & PP5415 & AtpA & only in N & 13 & ND & ND \\
\hline Glycogen debranching & PP4055 & $G \lg X$ & 12.3 & 31 & 2.4 & n.s. \\
\hline Electron transfer flavoprotein & PP4203 & & 4.5 & 36 & 0.90 & n.s. \\
\hline Succinate dehydrogenase & PP4191 & SdhA & 3.9 & 23 & 2.8 & n.s. \\
\hline NADH dehydrogenase I & PP4123 & NuoF & 2.9 & 15 & 2.4 & n.s. \\
\hline Glycosyl hydrolase & PP4053 & & 2.6 & 21 & 3.0 & n.s. \\
\hline Phosphoenolpyruvate synthase & PP2082 & PpsA & 2.4 & 24 & 1.5 & n.s. \\
\hline Acetoin dehydrogenase $\beta$-sub & PP0554 & AcoB & only in C & 23 & -4.0 & 0 \\
\hline Acetoin dehydrogenase & PP0553 & AcoC & only in $C$ & 10 & -5.3 & 0 \\
\hline Malate synthase & PP0356 & GlcB & -9.1 & 9 & -1.2 & n.s. \\
\hline Aldehyde dehydrogenase & PP0545 & GlcB & -5.9 & 19 & -1.9 & n.s. \\
\hline thioredoxin reductase & PP0786 & $\operatorname{TrxB}$ & -5.6 & 11 & 1.3 & n.s. \\
\hline Isocitrate lyase & PP4116 & AceA & -4.2 & 19 & 1.3 & n.s. \\
\hline Isocitrate dehydrogenase & PP4011 & ICD & -2.1 & 14 & 1.1 & n.s. \\
\hline \multicolumn{7}{|l|}{ Fatty acid metabolism } \\
\hline 3-hydroxyacyl-CoA dehydrogenase & PP2047 & & only in $\mathrm{N}$ & 18 & 20.9 & 0 \\
\hline Acetyl-CoA acetyltransferase & PP2051 & AtoB & only in $\mathrm{N}$ & 20 & 27.9 & 0 \\
\hline acetyl-CoA carboxylase & PP0558 & $\mathrm{AccC}-1$ & 8.3 & 27 & 1.3 & n.s. \\
\hline Fatty oxidation complex $\alpha$-sub & PP2136 & $\mathrm{FadB}$ & 3.1 & 13 & 2.3 & n.s. \\
\hline 3-oxoacyl-CoA thiolase & PP2137 & FadA & 3.0 & 23 & 2.4 & n.s. \\
\hline Fatty-acid CoA ligase & PP0763 & & -2.9 & 15 & -1.1 & n.s. \\
\hline
\end{tabular}


Table 4 Change in protein expression in response to nitrogen and carbon-nitrogen limitation in comparison with carbon-limitation (Continued)

\begin{tabular}{|c|c|c|c|c|c|c|}
\hline \multicolumn{7}{|l|}{ Transport and binding protein } \\
\hline Outer membrane porin & PP2089 & OprF & 5.4 & 17 & 1.4 & n.s. \\
\hline$A B C$ transporter & PP1726 & & -25.0 & 15 & 1.2 & n.s. \\
\hline \multicolumn{7}{|l|}{ Amino acid transport and biosynthesis } \\
\hline Branched-chain amino acid ABC & PP4864 & & only in N & 9 & -1.1 & n.s. \\
\hline Amino acid biosynthesis & PP5046 & $G \ln A$ & 16.0 & 17 & 1.5 & n.s. \\
\hline Hydantoin racemase & PP4310 & & 8.8 & 15 & 1.2 & n.s. \\
\hline General amino acid $A B C$ transporter & PP1300 & AapP & 4.0 & 16 & 1.1 & n.s. \\
\hline amino acid $A B C$ transporter & PP1071 & & only in C & 23 & -2.0 & n.s. \\
\hline amino acid $A B C$ transporter & PP0282 & & -33.3 & 15 & -1.2 & n.s. \\
\hline Branched-chain amino acid ABC & PP4867 & & -16.7 & 11 & 1.8 & n.s. \\
\hline Dipeptide ABC transporter & PP0885 & & -5.0 & 22 & 1.2 & n.s. \\
\hline Amino acid biosynthesis & PP0671 & GlyA-2 & -3.6 & 20 & -1.3 & n.s. \\
\hline \multicolumn{7}{|l|}{ Cell envelope } \\
\hline Outer membrane protein $\mathrm{H} 1$ & PP1185 & OprH & only in $N$ & 8 & 6.6 & 0.01 \\
\hline \multicolumn{7}{|l|}{ Cellular processes } \\
\hline Small multidrug resistance & PP4930 & & 4.9 & 216 & 1.1 & n.s. \\
\hline superoxide dismutase & PP0915 & SodB & -20.0 & 4 & -1.3 & n.s. \\
\hline \multicolumn{7}{|l|}{ DNA interactions } \\
\hline Transcriptional regulator, LysR & PP5375 & & -12.5 & 5 & -1.5 & n.s. \\
\hline C4-type zinc finger protein & PP4693 & & -11.1 & 5 & 1.4 & n.s. \\
\hline \multicolumn{7}{|l|}{ Protein fate } \\
\hline ATP-dependent Clp protease & PP2300 & & only in N & 7 & 1.2 & n.s. \\
\hline \multicolumn{7}{|l|}{ Protein synthesis } \\
\hline Elongation factor-G & PP0451 & FusA-1 & 20.0 & 26 & 1 & n.s. \\
\hline Hypotetical protein & PP2050 & & 9.4 & 10 & 28.4 & 0 \\
\hline Purine ribonucleotide biosynthesis & PP0722 & PrsA & 6.6 & 24 & 2.0 & n.s. \\
\hline Cell division & PP1342 & FtsZ & -7.1 & 5 & 1.0 & n.s. \\
\hline Nucleoside interconversions & PP0849 & NDK & -3.3 & 6 & 1.2 & n.s. \\
\hline Biosynthesis of co-factors & PP0842 & IscS-1 & -2.9 & 18 & 1.3 & n.s. \\
\hline Chemotaxis and motility & PP4366 & FliL & -2.3 & 7 & 1.3 & n.s. \\
\hline
\end{tabular}

\footnotetext{
${ }^{*}$ Bold font indicates matching between protein and transcript changes

${ }^{\mathrm{a}}$ Amount of peptides utilized for protein identification

$N D$, Not determined

n.s., $P$-value not significant $(>0.05)$
}

expression of the F0F1-type ATP synthase might be necessary for the cell in order to produce ATP molecules via the loss of proton-motive force, since high PHA yields decrease intracellular levels of ATP [56]. This effect might trigger different expression patterns from enzymes in the TCA cycle which is an important source of ATP generation along with the electron transport chain. As for the activity of the Krebs cycle, several genes were repressed under the dual limitation condition (Table 2). At the protein level only one enzyme, isocitrate dehydrogenase ICD (encoded by PP_4011), showed a fold change less than 2 (Table 3 ). The deficiency in the TCA cycle was confirmed by the metabolome analysis, where the increase in the pool size of succinate is a direct consequence of the repression of the $s d h C$ and $s d h D$ genes (Figure 3, Table 2). The quantitative increase of fumarate and malate was also triggered by the dual limitation. As catabolism and anabolism are tightly coupled under carbon limitation, the cell may coordinate the energy requirement in such a way that no overflow of carbon is present. When both carbon and nitrogen are the limiting nutrients simultaneously, the gluconeogenesis pathway responded by repressing the genes tpiA and gap-2, which coordinate carbon re-funneling in the Krebs cycle and the conversion rates of dihydroxyacetone phosphate and glyceraldehyde3-phosphate (Figure 3). The findings suggest that the carbon catabolic repression observed in the TCA cycle can be attributed to the high expression of the nitrogen regulatory protein NtrC (encoded by PP_5048) 
(Table 3), which is believed to control such an effect under nitrogen limitation [57].

High-energy compounds The strict nitrogen-limited cultures differ in their response to energy requirement relative to the $\mathrm{CN}$-limited cultures, principally due to the elevated level of enzymes participating in the Krebs cycle. Succinyl-CoA synthase SucD (encoded by PP_4185), which participates in the synthesis of the high-energy compounds ATP and GTP, was identified in cells only under strict nitrogen limitation. Examining the metabolome, we found a decreased pool size of metabolites down- and up-stream of succinate dehydrogenase, namely succinate and fumarate, respectively (Figure 4). All together it appears that the TCA cycle plays an important role in providing the necessary energy to the cell when PHAs are accumulated in increased proportion.

Employing 2-D gels, we also identified a particular modulation of another important enzyme in the cycle, isocitrate dehydrogenase ICD (encoded by PP_4011), which can be repressed by various mechanisms together with the low expression of ICD, two enzymes of the glyoxylate shunt, isocitrate lyase (encoded by PP_4116) and malate synthase (encoded by PP_0356), were significantly downregulated at strict nitrogen limitation. As such, this phenomenon can be directly related to the repression of the glyoxylate shunt, resulting in the downregulation of malate, which is the main precursor for oxaloacetate synthesis and is known as an essential compound for increasing the flux of acetyl-CoA into the TCA cycle [58]. In this sense, the inactivation of isocitrate lyase and isocitrate dehydrogenase in KT2442 led to the enhancement of PHAs when gluconate was used as the carbon source [58]. The inactivation of the glyoxylate shunt including the downregulation of malate synthase (GlcB) regulates the concentration of malate. Moreover, downregulation of isocitrate dehydrogenase (ICD) had a direct influence on the pool size of 2-ketoglutarate and consequently on glutamate formation. The cell triggered the activation of glutamine synthase $(\mathrm{G} \ln \mathrm{A})$ to form glutamine to counteract the decreased pool of precursor for the synthesis of amino acids. In this respect, the metabolome profile showed an increase in the concentration of glutamine under $\mathrm{CN}$ vs. C limitation. No change in glutamine concentration was observed at $\mathrm{N}$ vs. $\mathrm{C}$ limitation, although $\mathrm{Gln} \mathrm{A}$ was also found upregulated. Another metabolite that is directly regulated by the expression of isocitrate dehydrogenase is citrate. Studies on bacteria and yeast subjected to nitrogen limitation $[59,60]$, have shown repression of isocitrate dehydrogenase. Morgunov and co-workers found an increased concentration of citrate in yeast probably caused by the high ratio of NADH/NAD ${ }^{+}$, which inhibits isocitrate dehydrogenase. Notably, after

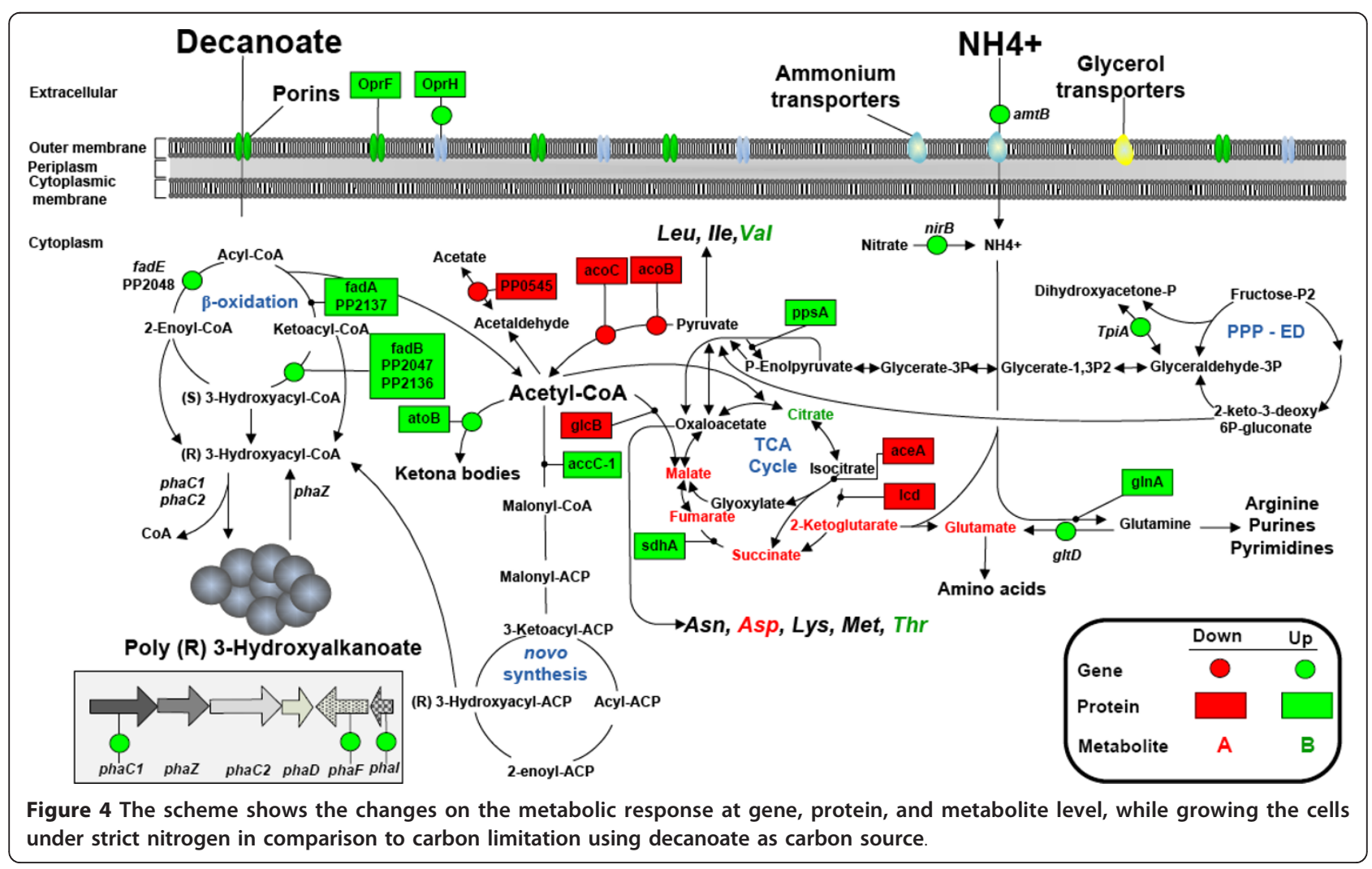


Table 5 Metabolites of known level changes in comparison to carbon-limiting condition

\begin{tabular}{lcc}
\hline & CN-limitation & N-limitation \\
\hline Entner-Doudoroff-pathway & up & up \\
Glucose & up & n.d. \\
2-Keto-3-deoxy-6Pgluconate & up & n.d. \\
3-Phosphoglycerate & & \\
TCA cycle & up & up \\
Citrate & down & down \\
2-Ketoglutarate & up & down \\
Succinate & up & down \\
Fumarate & up & down \\
Malate & & \\
Amino acids & down & down \\
Aspartate & up & n.d. \\
Cysteine & down & down \\
Glutamate & up & up \\
Glutamine & up & up \\
Glycine & up & n.d. \\
Isoleucine & n.d. & down \\
Ornithine & n.d. & up \\
Serine & n.d. & up \\
Threonine & up & down \\
Tyrosine & up & up \\
Valine & & \\
n.d.Not dined &
\end{tabular}

n.d., Not defined

comparing $\mathrm{N}$ vs. $\mathrm{C}$ and $\mathrm{CN}$ vs. $\mathrm{C}$, the pool size of citrate increased under both conditions (Table 5). Although the expression of isocitrate dehydrogenase was found to be significantly reduced under dual limitation, the inactivation was not accompanied by a downregulation of enzymes belonging to the glyoxylate pathway, suggesting a distinct regulatory system in this particular environment.

Electron transport chain Another important finding while comparing $\mathrm{N}$ vs. $\mathrm{C}$ limitation was the high induction of genes encoding the cytochrome o ubiquinol oxidase Cyo (encoded by PP_0813-0814) (Table 2). Cyo is a terminal oxidase of the electron transport chain which is believed to sense the energetic state of the cell, thus controlling the catabolic pathways and the expression of different genes [61]. In addition, terminal oxidases are highly regulated by oxygen concentration $[62,63]$. Due to the high oxygen concentration supplied to the bioreactor in order to keep the oxygen tension above $20 \%$, it is most likely that such an environment affects the composition of the electron transport chain. One possible explanation for the reorganization of the terminal oxidase under strict nitrogen limitation, is to optimize the energy generation in the cell [63] since a remarkable energy accumulation in the polyester form is present. In addition, Cyo levels have been shown as being responsible for decreasing the expression level of many promoters in P. putida including the PalkB promoter (for alkane assimilation). Furthermore, rather than a carbon catabolic repression, this effect has been postulated as a general physiological control mechanism [64]. Whether or not Cyo modulates the expression of genes under strict nitrogen limitation is still a question to be answered. There is a clear correlation between the TCA cycle and the electron transport chain, as shown by the high expression of the protein succinate dehydrogenase (4-fold change) which stimulates the cytochrome o ubiquinol oxidase by supplying electrons directly to it.

The overflow metabolism is one of the repeated trends of chemostats subjected to strict nitrogen limitation [14]. Since the exo-metabolite profile did not contain any secondary metabolites under this condition, $P$. putida KT2442 seems to arrange its metabolism in such a manner that it blocks energy-spilling by strongly repressing enzymes involved in the pyruvate and acetate pathways (acoA, acoB, acoC, PP_0545) (Table 3), thus preventing the shortage of partially oxidized metabolites [65]. This may be desirable because of the huge channeling of the consumed carbon (reflected in energy storage) towards polyester synthesis. Despite the dowregulation of those enzymes in the pyruvate and acetate pathways where acetyl-CoA is needed, there was a high expression of isoacetyl-CoA carboxylase and biosynthetic thiolase, which are the first enzymes responsible for channeling acetyl-CoA to de novo fatty acid and ketona bodies biosynthesis, respectively. Interestingly, it seems most likely that $P$. putida KT2442 channels the remaining acetyl-CoA into storage compounds by activating those pathways to save energy for later consumption (Figure 4).

\section{(iv) Nitrogen and amino acid metabolism}

As seen in Tables 2 and 3, the nitrogen regulatory protein P-II GnlK (encoded by PP_5234) showed a large change in both mRNA abundance and protein level, when Pseudomonas putida was subjected to dual limitation. This was not the case when we examined the proteome profile from strict nitrogen-deprived cells, since the spot for this enzyme did not show differential expression compared to the carbon-limited cultures. The expression of GnlK is led by the nitrogen availability via the nitrogen transcriptional regulator $\mathrm{NtrC}$ in $P$. putida KT2442 [66]. We also found that KT2442 displays the upregulation of $\mathrm{NtrC}$ when both carbon and nitrogen were completely depleted (Table 3 ). NtrC also modulates the expression of the $g \ln A$ gene (Hua et al., 2004), which is positioned upstream in the $\operatorname{gln} A-n \operatorname{tr} A B$ operon in Escherichia coli. Hervas and co-workers showed NtrC-dependency for the $(g \ln A)$ gene in KT2442, postulating that it could be part of an operon together with $(n \operatorname{tr} B)$ and $(n \operatorname{tr} C)$ genes, like in 
enterobacteria. Notably, GlnA exhibited the highest levels of induction among the proteins associated to amino acid biosynthesis (Table 3 ) in the case of strict nitrogen limitation. The condition also caused significant repression of several enzymes that were identified as serine hydroxymethyltransferase GlyA, putative hydantoin racemase (encoded by PP_4310), and branched-chain amino acid aminotransferase IlvE. In the valine, leucine, and isoleucine metabolic pathway IlvE has a double function to either act together with leucine dehydrogenase in the synthesis/degradation of leucine or in the degradation of valine and isoleucine to glutamate by transferring nitrogenous groups. Another enzyme responsible for the turnover of certain amino acids in the same family is GlyA, which carries out the conversion of glycine by transferring one-carbon group, giving serine as a product. Furthermore, it catalyzes the reaction of glycine with acetaldehyde to form threonine. Particularly, the downregulation of the periplasmic glutaminase-asparaginase protein occurred solely under strict nitrogen limitation. This protein is responsible for the uptake of the acidic amino acids, e.g. aspartate and glutamate [67]. Carbon catabolite repression of the periplasmic glutamate/aspartate transporter took place when KT2440 was exposed to glucose or mono- and dicarboxylic acids [68]. However, the metabolome profile showed a decrease in the pool size of fumarate and succinate (Table 5). Therefore, there may be another system which drives the transport selectivity described here.

\section{(v) Stress response proteins}

Besides their primary feature as a reservoir of energy and carbon, PHAs have displayed a key role in conferring robustness to the bacteria under unfavorable conditions, such as temperature, UV irradiation, chemicals, and osmotic pressure [69]. In contrast, based on the high polyester accumulation within the cell (Table 1), PHAs have also been postulated to act as a stressor, especially concerning protein synthesis and the activation of various protective proteins[70]. It is worth noting that all studies which stated such a stress produced by the polyester inclusion to the cell, have been performed in metabolically engineered E. coli [70-72].

In the current study a stress response of the cell while growing under $\mathrm{CN}$ - and $\mathrm{N}$-limitation can be seen. The high expression level of elongation factor enzymes is the first indicator of such an effect. The protein abundance of TuF-2 (encoded by PP_0452, Table 3), one of the Tuelongation factor enzymes, was extremely high under $\mathrm{CN}$ limitation. Besides its primarily role of binding and transporting the proper codon-specified aminoacyltRNA to the aminoacyl site of the ribosome, TuF-2 also has chaperon-like functions that enhance protein folding and stress protection[73]. Strict nitrogen-limited cultures exhibit overexpression of the elongation factor FusA-1 (encoded by PP_0451, Table 3), which is a GTPase (classified as a G-elongation factor) that is involved in the translocation of bacterial ribosomes along messenger RNA during protein biosynthesis [74]. On the other hand, the protease enzyme PP_2300, which is involved in hydrolysis of proteins to small peptides, was strongly induced in the presence of excess carbon (Table 3). So far, the decreased expression level of Tu-elongation factor has been related to the reduced capability of a metabolically engineered Escherichia coli to synthesize proteins (Han et al., 2001). However, E. coli does not naturally accumulate PHAs, therefore it is not surprising that KT2442 showed a different proteome pattern for these elongation factor enzymes. Indeed, the normal protein synthesis machinery is affected by the shortage of nitrogen; thereby the cell may react in such a way that guarantees the biosynthesis of the main building blocks (amino acids) of these macromolecules. In addition, the induction of the gene encoding the chaperonin 10 GroES (Table 2) was another metabolic adaptation against the stress produced by the nitrogen limitation. Han and colleagues also observed a high level expression of several heat shock proteins, arguing that the polyester inclusion disturbs the normal intracellular architecture due to its direct contact with the chromosome, resulting in activation of the heat shock response. Nevertheless, GroES also mediates protein folding. We suggest that this may be the principal reason for its incorporation since the genes coding the phasin enzymes were found to be induced (Table 1). The phasins prevent the disturbance of intracellular architecture by forming a protein layer covering the hydrophobic surface of the PHAs, thus creating a protective barrier between the core of the granule and the cytoplasm [6]. Very recently, we have demonstrated that the phasin $\mathrm{PhaF}$ is involved in granule cell localization and granule segregation during cell division by interaction with the chromosome [50]. Based on our results, we cannot elucidate whether or not phasins enzymes, PhaF or PhaI, have an influence on stress protein formation. To address this question, mutants strain deficient of genes encoding for PhaF and PhaI should be generated and assessed, by comparing them against the wild-type strain at the proteomic level under well-defined conditions (chemostat).

\section{Conclusions}

By combining measurements of transcriptomics, proteomics, and metabolomics, under well-controlled nutrient limitations, we have shown that the underlying cellular wiring is remarkably different when two nutrients are limiting at the same time, as compared to those under single limitation. We have captured the response of $P$. 
putida KT2442 to the shift in resource distribution and how these changes activate/repress several metabolic pathways along with transporter systems. We have found that the modulation of the expression of outer membrane proteins - in particular porins - under nitrogen and dual limitation correlates with the specific uptake rate of decanoate within the chemostat. We have shown that these two conditions also promote the overexpression of many transporters for scavenging nitrogen sources. The PHA content under nitrogen limitation was found to be the highest, followed by dual limitation and carbon limitation. The residual biomass was not constant for dual- and strict nitrogen-limiting growth, showing a different feature in comparison to other $P$. putida strains. Furthermore, the high accumulation of PHA under carbon limitation is a result of the constant channeling of precursors for PHA biosynthesis since no significant difference could be observed within the $\beta$ oxidation pathway at any omic level, when compared to dual limitation. Regarding energy generation, genes and proteins belonging to the electron transport chain system were found significantly upregulated when there was a considerable amount of PHA stored in the cell. To overcome the stress caused by the shortening of precursors for amino acid synthesis (nitrogen) and, consequently protein production, elongation factors along with chaperons guarantee the biosynthesis of the main building blocks (amino acids) of these macromolecules.

The systems approach applied in this study has enabled us to gain substantial insights into the metabolic adaptation of Pseudomonas putida KT2442 to nutrient limitation. Owing to its comprehensiveness and integration, the knowledge generated will be of great assistance on the development of further metabolic engineering work in this versatile organism to both enhance and diversify the production of PHAs. Our findings, especially concerning the dual limitation that uses both the carbon and nitrogen sources in the most economical manner, have brought an alternative to fulfill one of the remaining gaps in further improving industrial production of PHAs.

\section{Methods}

\section{Culture conditions and bacterial strain}

Pseudomonas putida KT2442 [75] was grown in a defined mineral medium (MM) consisting of (per liter) $12.8 \mathrm{~g} \mathrm{Na}_{2} \mathrm{HPO}_{4} .7 \mathrm{H}_{2} \mathrm{O}, 3 \mathrm{~g} \mathrm{KH}_{2} \mathrm{O}_{4}, 1 \mathrm{~g} \mathrm{NH}_{4} \mathrm{Cl}, 0.5 \mathrm{~g}$ $\mathrm{NaCl}$, supplemented with $0.12 \mathrm{~g}$ of $\mathrm{MgSO}_{4} \cdot \mathrm{H}_{2} \mathrm{O}$, and trace elements $\left(\mathrm{mg} \cdot \mathrm{l}^{-1}\right)$ : $6.0 \mathrm{FeSO}_{4} .7 \mathrm{H}_{2} \mathrm{O}, 2.7 \mathrm{CaCO}_{3}, 2.0$ $\mathrm{ZnSO}_{4} \cdot \mathrm{H} 2 \mathrm{O}, 1.16 \mathrm{MnSO}_{4} \cdot \mathrm{H}_{2} \mathrm{O}, 0.37 \mathrm{CoSO}_{4} .7 \mathrm{H}_{2} \mathrm{O}, 0.33$ $\mathrm{CuSO}_{4} .5 \mathrm{H}_{2} \mathrm{O}, 0.08 \mathrm{H}_{3} \mathrm{BO}_{3}$ and $0.1 \%$ (v/v) TEGO antifoam D 2310 (EVONIK Industries, Essen, Germany). Sodium decanoate (98\% purity, Sigma-Aldrich) was used as a single carbon source in concentrations ranging from 1.90 to $8.70 \mathrm{~g} \cdot \mathrm{l}^{-1}$ (Table 1). For the preparation of the feeding solution, MM was mixed with sodium decanoate and TEGO antifoam. After mixing it, the solution was autoclaved for $25 \mathrm{~min}$ at $121^{\circ} \mathrm{C}$. Once the bottle reached room temperature, it was placed into the clean bench where sterile trace elements solution and $\mathrm{MgSO}_{4} \cdot \mathrm{H}_{2} \mathrm{O}$ (by filtration) were added. Continuous cultivations were carried out under aerobic conditions at a dilution rate $(D)$ of $0.1 \mathrm{~h}^{-1}$, working volume of 0.8 liter in 1 liter top-bench BIOSTAT B1 bioreactor (Sartorius B Systems $\mathrm{GmbH}$, Melsungen, Germany) at $30^{\circ} \mathrm{C}$, constant stirring speed 700 r.p.m., and the $\mathrm{pH}$ was maintained at 7.0 by adding $2 \mathrm{M} \mathrm{H}_{2} \mathrm{SO}_{4}$. The working volume was kept constant by removing the fermentation broth through a peristaltic pump and recording the weight with a balance placed under the bioreactor. The aeration rate was set at $1 \mathrm{l} \cdot \mathrm{min}^{-1}$ using a mass flow controller (PR4000, MKS Instruments, Wilmington, MA, USA), a mixture of air and pure oxygen was used to ensure that the dissolved oxygen was above $30 \%$ of air saturation. A paramagnetic gas analyzer (Servomex Xentra 4100, USA) to record online the concentrations of carbon dioxide and oxygen in the course of the process was coupled to the gas outlet of the bioreactor.

\section{Analytical procedures}

Once the considered steady state was attained, - i.e. that the optical density of the biomass, dissolved oxygen concentration, and exhaust gas concentration remained constant for at least four residence times - samples from chemostat cultures were taken using a peristaltic pump and processed as follows:

\section{Cell and ammonium concentration}

Cellular dry weight was determined by centrifuging $5 \mathrm{ml}$ samples of the culture broth for $10 \mathrm{~min}$ at $4^{\circ} \mathrm{C}$ and $10,000 \mathrm{rpm}$ (centrifuge $5810 \mathrm{R}$, Eppendorf, Germany) in pre-weighed tubes, washing the cell pellets once with distilled water and drying them at $80^{\circ} \mathrm{C}$ until a constant weight was obtained. Cell growth was recorded by measuring the optical density at $600_{\mathrm{nm}}$ (Ultraspect 2000 UV/VIS, Hitachi, Japan). The ammonium concentration in the cell-free supernatant was measured using the LCK 303 kit of Hach Lange (Danaher, USA). The detection limit of this method was $1.9 \mathrm{mg}$ of $\mathrm{N} /$ liter.

\section{Fatty acid and PHA analysis}

PHA compositions of the polymer produced, as well as the cellular PHA content and fatty acid concentration were determined by gas chromatography (GC) and mass spectrometry (MS) of the methanolyzed fatty acid and polyester. Methanolysis procedure was carried out by suspending 5-10 $\mathrm{mg}$ of lyophilized aliquots in $2 \mathrm{ml}$ of chloroform and $2 \mathrm{ml}$ of methanol containing 15\% sulfuric acid and $0.5 \mathrm{mg} \mathrm{ml}^{-1} 3$-methylbenzoic acid (internal standard) and then incubated at $100^{\circ} \mathrm{C}$ for $4 \mathrm{~h}$. After 
cooling, $1 \mathrm{ml}$ of demineralized water was added and the organic phase containing the resulting methyl esters of monomers was analysed by GC-MS [76]. An Agilent (Waldbronn, Germany) series 7890A coupled with a 5975 C MS detector (EI, $70 \mathrm{eV}$ ) and a split-splitless injector were used for analysis. An aliquot $(1 \mathrm{ml})$ of organic phase was injected into the gas chromatograph at a split ratio of 1:50. Separation of compounds was achieved using a HP-5 MS capillary column (5\% phenyl$95 \%$ methyl siloxane, $30 \mathrm{~m} \times 0.25 \mathrm{~mm}$ i.d. $\times 0.25 \mathrm{~mm}$ film thickness). Helium was used as carrier gas at a flow rate of $0.9 \mathrm{ml} \mathrm{min}^{-1}$. The injector and transfer line temperature were set at $275^{\circ} \mathrm{C}$ and $300^{\circ} \mathrm{Crespectively.} \mathrm{The}$ oven temperature programme was: initial temperature $80^{\circ} \mathrm{C}$ for $2 \mathrm{~min}$, then from $80^{\circ} \mathrm{C}$ up $150^{\circ} \mathrm{C}$ at a rate of $5^{\circ}$ $\mathrm{C} \min ^{-1}$ and finally up $200^{\circ} \mathrm{C}$ at a rate of $10^{\circ} \mathrm{C} \mathrm{min}^{-1}$. EI mass spectra were recorded in full scan mode $(\mathrm{m} / z$ 40550).

\section{Exometabolite profile}

1D ${ }^{1} \mathrm{H}$ nuclear magnetic resonance spectra were recorded on a Bruker AVANCE DMX600 NMR spectrometer at $300 \mathrm{~K}$ of aqueous centrifuged supernatant containing $10 \% \mathrm{D}_{2} \mathrm{O}$ to give a final volume of $0.66 \mathrm{ml}$. The water signal was suppressed using standard Bruker software. For comparison purposes, spectra of solutions of initial medium containing antifoam and sodium decanoate were recorded. In order to acquire an appropriate signal-to-noise ratio, spectra were recorded under standard conditions (sweep width: $20 \mathrm{ppm}$, acquisition time: $1.36 \mathrm{~s}$, pulse delay: $1 \mathrm{~s}$, number of scans: 1400 , Bruker program noesypr1d).

\section{Transcriptomics}

Aliquots of $10 \mathrm{ml}$ of culture broth were placed in RNAprotect buffer (Qiagen), cell pellets were further frozen at $-80^{\circ} \mathrm{C}$. Isolation of total RNA was performed using RNeasy kits (Qiagen), according to the instructions provided by the manufacturer. Progenika Biopharma (Vizcaya, Spain) P. putida Oligonucleotides Arrays were used for all transcriptional analyses. Fluorescently labelled cDNA for microarray hybridizations was obtained by using the SuperScript Indirect cDNA Labeling System (Invitrogen), as recommended by the supplier. In brief, $20 \mu \mathrm{g}$ of total RNA was transformed to cDNA with Superscript III reverse transcriptase using random hexamers as primers, and including aminoallylmodified nucleotides in the reaction mixture. After cDNA purification, the Cy3 or Cy5 fluorescent dyes (Amersham Biosciences) were coupled to the aminomodified first-strand cDNA. Labeling efficiency was assessed using a NanoDrop ND1000 spectrophotometer (NanoDropTechnologies). Equal amounts of Cy3- or Cy5-labelled cDNAs, one of them corresponding to the control and the other one to the condition to be analyzed, were mixed and dried in a Speed-Vac. The scanning was done with a GenePix 400B Scanner (Molecular Devices Corporation, Sunnyvale, California, USA.) at a $10 \mu \mathrm{m}$ resolution. The images were quantified with GenePix Pro 5.1. Images from Cy3 and Cy5 channels were equilibrated and captured with a GenePix 4000B (Axon) and spots were quantified using GenPix Pro 5.1 software (Axon). The microarrays were analyzed using various packages from the Bioconductor suite [77]. The results of image analysis were read in using the 'limma' package. The quality of the chips was analyzed with the 'arrayQualityMetrics' package [78]. The intensity values were background-corrected using the "normexp" method of the limma package [79] and normalized with the variance stabilization method [80]. The significantly differentially expressed genes were identified by fitting the linear model (using the functions 'ImFit' and 'eBayes' from the 'limma' package) [81]. Genes for which the adjusted p-value (by Benjamini-Hochberg method) was lower than 0.05 and the fold change exceeded 2 in either direction were assumed to be significantly expressed.

\section{Proteomics}

For protein extraction, cells were centrifuged at $8000 \mathrm{~g}$ for 15 minutes (centrifuge $5810 \mathrm{R}$, Eppendorf, Germany), the pellet was washed twice with PBS solution ( $\mathrm{pH}$ 7.4). The resulting pellet was resuspended in lysis buffer consisting of $7 \mathrm{M}$ urea, $2 \mathrm{M}$ thiourea, $4 \% \mathrm{w} / \mathrm{v}$ CHAPS, $20 \mathrm{mM}$ Tris base and $30 \mathrm{mM} 1.4$ dithiothreitol (DTT), together with protease inhibitor cocktail tablets. The lysis was complemented by sonication (Labsonic U, B. Braun, Germany. The resulting solution was ultracentrifuged (Sorval ultracentrifuge OTD-Combi, Thermo Electron, Germany) at $12000 \mathrm{~g}, 4^{\circ} \mathrm{C}$ for $30 \mathrm{~min}$. The supernatant, corresponding to the soluble protein fraction, was aliquoted and further precipitated by using the 2-D Clean-Up Kit (GE Healthcare, USA). Analytical determinations were carried out with $100 \mathrm{mg}$ of protein mixture determined by Bradford (Bio-Rad protein assay, Bio-Rad, USA), diluted up to $300 \mathrm{ml}$ with rehydration solution (7 M urea; $5 \% \mathrm{w} / \mathrm{v}$ Serdolit; $2 \mathrm{M}$ thio-urea; $4 \%$ w/v CHAPS; $20 \mathrm{mM}$ Trizma base) in the presence of ampholytes and under reducing conditions, on ReadyStrip IPG strips, $17 \mathrm{~cm}$, pH 3-10 (Bio-Rad, USA). Passive rehydration was carried out for $2 \mathrm{~h}$ at $20^{\circ} \mathrm{C}$ on the focusing tray. Samples were covered with silicon oil to avoid dehydration. Active rehydration was performed at $50 \mathrm{~V}$ for $12 \mathrm{~h}$. Isoelectric focusing was done at a final voltage of $10000 \mathrm{~V}$ on ProteanIEF cell (Bio-Rad, USA) until reaching $75 \mathrm{kVh}$. Focused samples were stored at $-70^{\circ} \mathrm{C}$ until the second dimension step. Focused ReadyStrip IPG strips were equilibrated first in equilibration buffer containing $6 \mathrm{M}$ urea, $0.375 \mathrm{M}$ Trizma base $(\mathrm{pH}$ 
8.6), $30 \% \mathrm{v} / \mathrm{v}$ glycerin, $2 \% \mathrm{w} / \mathrm{v}$ SDS and $2 \% \mathrm{w} / \mathrm{v}$ DTT and later in the same buffer replacing DTT with $2.5 \%$ $\mathrm{w} / \mathrm{v}$ iodoacetamide. After equilibration, second-dimension separation was performed on $12-15 \%$ gradient SDSpolyacrylamide $20 \times 20 \mathrm{~cm}$ gels with the focused sample embedded in $0.5 \%$ IEF agarose in a Protean Plus Dodeca Cell (Bio-Rad, USA) at $100 \mathrm{~V}$ overnight. The gels were fixed in $10 \%$ trichloroacetic acid solution for a minimum of $3 \mathrm{~h}$, stained with $0.1 \% \mathrm{w} / \mathrm{v}$ Coomassie Brilliant Blue G-250 solution overnight and finally de-stained with distilled water. Images of the 2-DE gels were captured with a molecular imager GS-800 calibrated densitometer (Bio-Rad, USA) and processed using Phoretix 2D image analysis software version 2004 (NonLinear Dynamics, $\mathrm{UK})$ for protein DE analysis. Differential expression was defined as the ratio of spot protein expression in a comparative image to the expression of a corresponding spot in a reference image. Up- and down-regulation of protein expression were considered when the $p$ value was less than 0.05 , and twofold (or higher), and 0.5-fold (or lower) DE values, correspondingly. Protein spots were excised manually from the gels. Spots were destained and digested overnight using sequence grade modified trypsin (Promega, USA). The peptides were eluted and desalted with ZipTip (Millipore, USA). For MALDI-TOF analysis, the samples were loaded along with a-cyano-4-hydroxycinnamic acid matrix. The target was then analyzed using an Ultraflex II ToF (Bruker Daltonics, USA). The resulting spectra were used for Peptide Mass Fingerprint (PMF) and analyzed using FlexAnalysis 2.0 and Biotools 2.2 software (Bruker Daltonics). Proteins were identified using an in-houselicensed Mascot search engine (version 2.1.0, Matrix Science, U.K.). The P. putida KT2440 database was searched using the MALDI TOF-MS data with carbamidomethyl cysteine as a fixed modification and oxidized methionine as a variable modification. Trypsin was specified as the proteolytic enzyme and up to two missed cleavages were allowed.

\section{Metabolomics}

For metabolite extraction, cells were centrifuged at 4629 $g$, $4^{\circ} \mathrm{C}$ for 3 minutes (centrifuge 5810 R, Eppendorf, Germany). The supernatant was discarded and the cell pellet was resuspended in $10 \mathrm{ml}$ pre-cooled $0.9 \% \mathrm{NaCl}(\mathrm{w} /$ v). After further centrifugation the supernatant was discarded to complete the washing step. Furthermore, the resulting cell pellet was resupended in $1.5 \mathrm{ml}$ cold methanol containing $60 \mu \mathrm{l}$ ribitol $\left(0.2 \mathrm{~g} \cdot \mathrm{l}^{-1}\right)$ as internal standard. To achieve cell lysis the tubes were incubated in an ultrasonic bath $\left(15 \mathrm{~min}, 70^{\circ} \mathrm{C}\right)$. After the samples were cooled down for $2 \mathrm{~min}$ by placing them on ice, 1.5 $\mathrm{ml}$ of deionized $\mathrm{H}_{2} \mathrm{O}$ was added and vortexed for $30 \mathrm{~s}$.
The addition of $1 \mathrm{ml}$ chloroform was followed by mixing and centrifugation $\left(9000 \mathrm{~g}, 4^{\circ} \mathrm{C}, 5 \mathrm{~min}\right) ; 1 \mathrm{ml}$ of the polar phase was subjected to a centrifugal-vacuum concentrator to allow evaporation. For derivatization, dried pellets were redissolved in $20 \mu \mathrm{l}$ pyridine, containing 20 $\mathrm{mg} \mathrm{ml}^{-1}$ methoxyamine hydrochloride, at $30^{\circ} \mathrm{C}$ for 90 min under shaking. After adding $32 \mu \mathrm{l} \mathrm{N}$-methyl-N-trimethylsilyltrifluoroacetamide, samples were incubated at $37^{\circ} \mathrm{C}$ for $30 \mathrm{~min}$, followed by incubation at room temperature for $90 \mathrm{~min}$ under continuous shaking. Finally, the samples were centrifuged at $14000 \mathrm{~g}$ for $5 \mathrm{~min}$ and the supernatant was used for GC-MS analysis. All samples were analysed within $24 \mathrm{~h}$ after derivatization. A retention index marker ( $\mathrm{n}$-alkanes ranging from $\mathrm{C} 10$... C36 in cyclohexane) was used to convert retention times to retention indices.

GC-MS analysis was performed on a FinniganTrace mass spectrometer (ThermoFinnigan, San Jose, USA). In summary, $1 \mu \mathrm{l}$ of the derivatized samples was injected in randomized sequence into a programmed temperature vaporizer in split mode $(1: 25)$ at $70^{\circ} \mathrm{C}$. After an initial time of 0.2 min the injector was ramped at $14^{\circ} \mathrm{C} \mathrm{s}^{-1}$ to a final temperature of $280^{\circ} \mathrm{C}$ and held for $5 \mathrm{~min}$. The gas chromatograph was equipped with a J\&W DB-5MS column (30 $\mathrm{m} \times 0.25 \mathrm{~mm}$ ID, $0.25 \mu \mathrm{m}$ film thickness). The GC was operated at constant flow of $1 \mathrm{ml} \mathrm{min}^{-1}$ helium. The temperature program started at $70^{\circ} \mathrm{C}$, held for 1 min, followed by a temperature ramping of $10^{\circ} \mathrm{C} \mathrm{min}^{-1}$ to a final temperature of $325^{\circ} \mathrm{C}$, which was held constant for $6 \mathrm{~min}$. The transfer line temperature was set to $275^{\circ}$ C. Ion source temperature was adjusted to $200^{\circ} \mathrm{C}$. Fullscan mass spectra of $\mathrm{m} / \mathrm{z} 40 . .460$ were collected at an acquisition rate of 2.5 scans $\mathrm{sec}^{-1}$. Solvent delay time was $4.5 \mathrm{~min}$. For data acquisition Xcalibur 1.2 (Thermo Scientific) was used.

All chromatograms were processed using MetaboliteDetector [82] for targeted analysis. The software supports automatically deconvolution of all mass spectra from a chromatogram and calculates the retention indices. The obtained mass spectra were matched against the reference with a minimum match factor of 0.75 . Compounds were annotated by retention index and mass spectra comparison to our inhouse library. Selected fragment ions unique for each individual metabolite were used for quantification. Finally, each compound was normalized by peak area from the internal standard (ribitol) and given cell dry weight.

\section{Calculations}

In the chemostat, the physiological parameters, as well as the PHA productivity where calculated according to the following equations: 
16. Egli T: On multiple-nutrient-limited growth of microorganisms, with special reference to dual limitation by carbon and nitrogen substrates. Antonie Van Leeuwenhoek 1991, 60(3):225-234.

17. Zinn M, Witholt B, Egli T: Dual nutrient limited growth: Models, experimental observations, and applications. J Biotechnol 2004, 113(13):263-279.

18. Escapa IF, Morales V, Martino VP, Pollet E, Averous L, Garcia JL, Prieto MA: Disruption of B-oxidation pathway in Pseudomonas putida KT2442 to produce new functionalized PHAs with thioester groups. Appl Microbiol Biotechnol 2011, 89(5):1583-1598.

19. Liu Q, Luo G, Zhou XR, Chen GQ: Biosynthesis of poly(3hydroxydecanoate) and 3-hydroxydodecanoate dominating polyhydroxyalkanoates by $\beta$-oxidation pathway inhibited Pseudomonas putida. Metab Eng 2011, 13(1):11-17.

20. de Eugenio LI, Galan B, Escapa IF, Maestro B, Sanz JM, Garcia JL, Prieto MA: The PhaD regulator controls the simultaneous expression of the pha genes involved in polyhydroxyalkanoate metabolism and turnover in Pseudomonas putida KT2442. Environ Microbiolo 2010, 12(6):1591-1603.

21. Ouyang SP, Luo RC, Chen SS, Liu Q, Chung A, Wu Q, Chen GQ: Production of polyhydroxyalkanoates with high 3-hydroxydodecanoate monomer content by fadB anf fadA knockout mutant of Pseudomonas putida KT2442. Biomacromolecules 2007, 8(8):2504-2511.

22. Sohn SB, Kim TY, Park JM, Lee SY: In silico genome-scale metabolic analysis of Pseudomonas putida KT2440 for polyhydroxyalkanoate synthesis, degradation of aromatics and anaerobic survival. Biotechnol $J$ 2010, 5(7):739-750

23. Puchalka J, Oberhardt MA, Godinho M, Bielecka A, Regenhardt D, Timmis KN, Papin JA, Martins dos Santos VA: Genome-scale reconstruction and analysis of the Pseudomonas putida KT2440 metabolic network facilitates applications in biotechnology. PLoS Comput Biol 2008, 4(10): e1000210.

24. Nogales J, Palsson BO, Thiele I: A genome-scale metabolic reconstruction of Pseudomonas putida KT2440: iJN746 as a cell factory. BMC Syst Biol 2008, 2:79.

25. Huijberts GNM, Eggink G: Production of poly(3-hydroxyalkanoates) by Pseudomonas putida KT2442 in continuous cultures. Appl Microbiol Biotechnol 1996, 46(3):233-239.

26. van Duuren JBJH: Optimization of Pseudomonas putida KT2440 as host for the production of cis, cis-muconate from benzoate Wageningen: Wageningen; 2011.

27. Follonier S, Panke S, Zinn M: A reduction in growth rate of Pseudomonas putida KT2442 counteracts productivity advances in medium-chainlength polyhydroxyalkanoate production from gluconate. Microbial Cell Factories 2011, 10(1):25.

28. Huijberts GNM, Eggink G, De Waard P, Huisman GW, Witholt B: Pseudomonas putida KT2442 cultivated on glucose accumulates poly(3hydroxyalkanoates) consisting of saturated and unsaturated monomers. Appl Environ Microbiol 1992, 58(2):536-544.

29. Kolkman A, Daran-Lapujade P, Fullaondo A, Olsthoorn MMA, Pronk JT, Slijper M, Heck AJR: Proteome analysis of yeast response to various nutrient limitations. Molecular Systems Biology 2006, 2:2006-0026.

30. Lu P, Vogel C, Wang R, Yao X, Marcotte EM: Absolute protein expression profiling estimates the relative contributions of transcriptional and translational regulation. Nat Biotech 2007, 25(1):117-124.

31. Verhoef $\mathrm{S}$, Ballerstedt $H$, Volkers RJM, De Winde JH, Ruijssenaars HJ: Comparative transcriptomics and proteomics of $p$-hydroxybenzoate producing Pseudomonas putida S12: Novel responses and implications for strain improvement. App/ Microbiolo Biotechnol 2010, 87(2):679-690.

32. Resch A, Leicht $S$, Saric M, Pásztor L, Jakob A, Götz F, Nordheim A: Comparative proteome analysis of Staphylococcus aureus biofilm and planktonic cells and correlation with transcriptome profiling. Proteomics 2006, 6(6):1867-1877.

33. Lee MV, Topper SE, Hubler SL, Hose J, Wenger CD, Coon JJ, Gasch AP: A dynamic model of proteome changes reveals new roles for transcript alteration in yeast. Mol Syst Biol 2011, 7:514

34. Saito K, Matsuda F: Metabolomics for functional genomics, systems biology, and biotechnology. Annual Review of Plant Biology 2010, 61:463-489

35. Martins Dos Santos VAP, Heim S, Moore ERB, Strätz M, Timmis KN: Insights into the genomic basis of niche specificity of Pseudomonas putida KT2440. Environ Microbiol 2004, 6(12):1264-1286.
36. Mobley HLT, Island MD, Hausinger RP: Molecular biology of microbial ureases. Microbiol Rev 1995, 59(3):451-480.

37. Burne RA, Chen YYM: Bacterial ureases in infectious diseases. Microbes and Infection 2000, 2(5):533-542.

38. Bellido F, Martin NL, Siehnel RJ, Hancock REW: Reevaluation, using intact cells, of the exclusion limit and role of porin OprF in Pseudomonas aeruginosa outer membrane permeability. J Bacteriol 1992, 174(16):5196-5203.

39. Hancock REW, Decad GM, Nikaido H: Identification of the protein producing transmembrane diffusion pores in the outer membranes of Pseudomonas aeruginosa PA01. Biochim Biophys Acta 1979, 554(2):323-331.

40. Peng $X, X u C$, Ren $H, L i n X, W u L$, Wang S: Proteomic analysis of the sarcosine-insoluble outer membrane fraction of Pseudomonas aeruginosa responding to ampicilin, kanamycin, and tetracycline resistance. J Proteome Res 2005, 4(6):2257-2265.

41. Trias J, Nikaido H: Protein D2 channel of the Pseudomonas aeruginosa outer membrane has a binding site for basic amino acids and peptides. J Biol Chem 1990, 265(26):15680-15684.

42. Ochs MM, Lu CD, Hancock REW, Abdelal AT: Amino acid-mediated induction of the basic amino acid-specific outer membrane porin OprD from Pseudomonas aeruginosa. J Bacteriol 1999, 181(17):5426-5432.

43. Bell A, Bains M, Hancock REW: Pseudomonas aeruginosa outer membrane protein OprH: Expression from the cloned gene and function in EDTA and gentamicin resistance. J Bacteriol 1991, 173(21):6657-6664.

44. Volkers RJM, De Jong AL, Hulst AG, Van Baar BLM, De Bont JAM, Wery J: Chemostat-based proteomic analysis of toluene-affected Pseudomonas putida S12. Environ Microbiol 2006, 8(9):1674-1679.

45. Steinbüchel A, Lutke-Eversloh T: Metabolic engineering and pathway construction for biotechnological production of relevant polyhydroxyalkanoates in microorganisms. Biochem Eng J 2003, 16(2):81-96.

46. Liu W, Chen GQ: Production and characterization of medium-chainlength polyhydroxyalkanoate with high 3-hydroxytetradecanoate monomer content by fadB and fadA knockout mutant of Pseudomonas putida KT2442. Appl Microbiol Biotechnol 2007, 76(5):1153-1159.

47. Olivera ER, Carnicero D, Jodra R, Miambres B, Garcia B, Abraham GA, Gallardo A, Roman JS, Garcia JL, Naharro G, et al: Genetically engineered Pseudomonas: A factory of new bioplastics with broad applications. Environ Microbiol 2001, 3(10):612-618.

48. Huisman GW, Wonink E, De Koning G, Preusting H, Witholt B: Synthesis of poly(3-hydroxyalkanoates) by mutant and recombinant Pseudomonas strains. Appl Microbiol Biotechnol 1992, 38(1):1-5.

49. Sun Z, Ramsay JA, Guay M, Ramsay BA: Carbon-limited fed-batch production of medium-chain-length polyhydroxyalkanoates from nonanoic acid by Pseudomonas putida KT2440. Appl Microbiol Biotechnol 2007, 74(1):69-77.

50. Galan B, Dinjaski N, Maestro B, De Eugenio LI, Escapa IF, Sanz JM, Garcia JL, Prieto MA: Nucleoid-associated PhaF phasin drives intracellular location and segregation of polyhydroxyalkanoate granules in Pseudomonas putida KT2442. Mol Microbiol 2011, 79(2):402-418.

51. Rehm BHA, Krüger N, Steinbüchel A: A new metabolic link between fatty acid de novo synthesis and polyhydroxyalkanoic acid synthesis. The phaG gene from Pseudomonas putida KT2440 encodes a 3-hydroxyacylacyl carrier protein-coenzyme a transferase. J Biol Chem 1998 273(37):24044-24051.

52. Huijberts GN, de Rijk TC, de Waard P, Eggink G: $13 C$ nuclear magnetic resonance studies of Pseudomonas putida fatty acid metabolic routes involved in poly(3-hydroxyalkanoate) synthesis. J Bacteriol 1994, 176(6):1661-1666.

53. Ren $Q$, de Roo G, Witholt B, Zinn M, Thony-Meyer L: Influence of growth stage on activities of polyhydroxyalkanoate (PHA) polymerase and PHA depolymerase in Pseudomonas putida U. BMC Microbiol 2010, 10(1):254.

54. Ren Q, de Roo G, Ruth K, Witholt B, Zinn M, Thony-Meyer L: Simultaneous Accumulation and Degradation of Polyhydroxyalkanoates: Futile Cycle or Clever Regulation? Biomacromolecules 2009, 10(4):916-922.

55. Garcia B, Olivera ER, Miambres B, Fernandez-Valverde M, Cacedo LM Prieto MA, Garcia JL, Martinez M, Luengo JM: Novel Biodegradable Aromatic Plastics from a Bacterial Source. J Biol Chem 1999, 274(41):29228-29241.

56. Ruiz JA, Lopez NI, Fernandez RO, Medez BS: Polyhydroxyalkanoate degradation is associated with nucleotide accumulation and enhances 
stress resistance and survival of Pseudomonas oleovorans in natural water microcosms. Appl Environ Microbiol 2001, 67(1):225-230.

57. Hervas AB, Canosa I, Santero E: Transcriptome analysis of Pseudomonas putida in response to nitrogen availability. J Bacterio/ 2008, 190(1):416-420.

58. Klinke S, Dauner M, Scott G, Kessler B, Witholt B: Inactivation of isocitrate lyase leads to increased production of medium-chain-length poly(3hydroxyalkanoates) in Pseudomonas putida. Appl Environ Microbiol 2000, 66(3):909-913.

59. Hua Q, Yang C, Oshima T, Mori H, Shimizu K: Analysis of Gene Expression in Escherichia coli in Response to Changes of Growth-Limiting Nutrient in Chemostat Cultures. Appl Environ Microbiol 2004, 70(4):2354-2366.

60. Morgunov IG, Solodovnikova NY, Sharyshev AA, Kamzolova SV, Finogenova TV: Regulation of NAD + -Dependent isocitrate dehydrogenase in the citrate producing yeast Yarrowia lipolytica. Biochem Mosc 2004, 69(12):1391-1398.

61. Rojo F: Carbon catabolite repression in Pseudomonas: Optimizing metabolic versatility and interactions with the environment. FEMS Microbiol Rev 2010, 34(5):658-684.

62. Kawakami T, Kuroki M, Ishii M, Igarashi $Y$, Arai H: Differential expression of multiple terminal oxidases for aerobic respiration in Pseudomonas aeruginosa. Environ Microbiol 2010, 12(6):1399-1412.

63. Morales G, Ugidos A, Rojo F: Inactivation of the Pseudomonas putida cytochrome o ubiquinol oxidase leads to a significant change in the transcriptome and to increased expression of the $\mathrm{ClO}$ and $\mathrm{cbb3}-1$ terminal oxidases. Environ Microbiol 2006, 8(10):1764-1774.

64. Dinamarca MA, Aranda-Olmedo I, Puyet A, Rojo F: Expression of the Pseudomonas putida OCT plasmid alkane degradation pathway is modulated by two different global control signals: Evidence from continuous cultures. J Bacteriol 2003, 185(16):4772-4778.

65. Russell JB, Cook GM: Energetics of bacterial growth: Balance of anabolic and catabolic reactions. Microbiol Rev 1995, 59(1):48-62.

66. Hervas AB, Canosa I, Little R, Dixon R, Santero E: NtrC-dependent regulatory network for nitrogen assimilation in Pseudomonas putida. $J$ Bacteriol 2009, 191(19):6123-6135.

67. Sonawane A, Kloppner U, Hovel S, Volker U, Rohm KH: Identification of Pseudomonas proteins coordinately induced by acidic amino acids and their amides: A two-dimensional electrophoresis study. Microbiology 2003, 149(10):2909-2918.

68. Sonawane A, Klöppner U, Derst C, Röhm KH: Utilization of acidic amino acids and their amides by pseudomonads: Role of periplasmic glutaminase-asparaginase. Arch Microbiol 2003, 179(3):151-159.

69. Zhao YH, Li HM, Qin LF, Wang HH, Chen GQ: Disruption of the polyhydroxyalkanoate synthase gene in Aeromonas hydrophila reduces its survival ability under stress conditions. FEMS Microbiol Lett 2007, 276(1):34-41.

70. Han MJ, Sang Sun Y, Sang Yup L: Proteome analysis of metabolically engineered Escherichia coli producing poly(3-hydroxybutyrate). J Bacteriol 2001, 183(1):301-308.

71. Kang Z, Wang Q, Zhang H, Qi Q: Construction of a stress-induced system in Escherichia coli for efficient polyhydroxyalkanoates production. Appl Microbiol Biotechnol 2008, 79(2):203-208.

72. Tessmer N, König S, Malkus U, Reichelt R, Pötter M, Steinbüchel A: Heatshock protein HspA mimics the function of phasins sensu stricto in recombinant strains of Escherichia coli accumulating polythioesters or polyhydroxyalkanoates. Microbiology 2007, 153(2):366-374.

73. Caldas TD, El Yaagoubi A, Richarme G: Chaperone properties of bacterial elongation factor EF-Tu. J Biol Chem 1998, 273(19):11478-11482.

74. Rodnina MV, Savelsbergh A, Katunin VI, Wintermeyer W: Hydrolysis of GTP by elongation factor $\mathrm{G}$ drives tRNA movement on the ribosome. Nature 1997, 385(6611):37-41.

75. Bagdasarian M, Lurz R, Ruckert B: Specific-purpose plasmid cloning vectors. II. Broad host range, high copy number, RSF 1010-derived vectors, and a host-vector system for gene cloning in Pseudomonas. Gene 1981, 16(1-3):237-247.

76. Lageveen RG, Huisman GW, Preusting H, Ketelaar P, Eggink G, Witholt B: Formation of Polyesters by Pseudomonas oleovorans: Effect of Substrates on Formation and Composition of Poly-(R)-3-Hydroxyalkanoates and Poly-(R)-3-Hydroxyalkenoates. Appl Environ Microbiol 1988, 54(12):2924-2932.
77. Gentleman RC, Carey VJ, Bates DM, Bolstad B, Dettling M, Dudoit S, Ellis B, Gautier L, Ge Y, Gentry J, et al: Bioconductor: open software development for computational biology and bioinformatics. Genome biology 2004, 5(10):R80.

78. Kauffmann A, Gentleman R, Huber W: arrayQualityMetrics - A bioconductor package for quality assessment of microarray data. Bioinformatics 2009, 25(3):415-416.

79. Ritchie ME, Silver J, Oshlack A, Holmes M, Diyagama D, Holloway A, Smyth GK: A comparison of background correction methods for twocolour microarrays. Bioinformatics 2007, 23(20):2700-2707.

80. Huber W, Von Heydebreck A, Sultmann H, Poustka A, Vingron M: Variance stabilization applied to microarray data calibration and to the quantification of differential expression. Bioinformatics 2002, 18(SUPPL 1): S96-S104.

81. Smyth GK: Linear models and empirical bayes methods for assessing differential expression in microarray experiments. Statistical Applications in Genetics and Molecular Biology 2004, 3(1):3.

82. Hiller K, Hangebrauk J, Jager C, Spura J, Schreiber K, Schomburg D: Metabolite detector: Comprehensive analysis tool for targeted and nontargeted GC/MS based metabolome analysis. Anal Chem 2009, 81(9):3429-3439.

doi:10.1186/1475-2859-11-34

Cite this article as: Poblete-Castro et al:: The metabolic response of $P$. putida KT2442 producing high levels of polyhydroxyalkanoate under single- and multiple-nutrient-limited growth: Highlights from a multilevel omics approach. Microbial Cell Factories 2012 11:34.

\section{Submit your next manuscript to BioMed Central and take full advantage of:}

- Convenient online submission

- Thorough peer review

- No space constraints or color figure charges

- Immediate publication on acceptance

- Inclusion in PubMed, CAS, Scopus and Google Scholar

- Research which is freely available for redistribution

Submit your manuscript at www.biomedcentral.com/submit
C Biomed Central 